\title{
Ground Processing Affordability for Space Vehicles
}

\author{
John Ingalls ${ }^{1}$ and Russell Scott ${ }^{2}$ \\ United Space Alliance, LLC, NASA Kennedy Space Center, FL, 32899
}

\begin{abstract}
Launch vehicles and most of their payloads spend the majority of their time on the ground. The cost of ground operations is very high. So, why so often is so little attention given to ground processing during development? The current global space industry and economic environment are driving more need for efficiencies to save time and money. Affordability and sustainability are more important now than ever. We can not continue to treat space vehicles as mere science projects. More RLV's (Reusable Launch Vehicles) are being developed for the gains of reusability which are not available for ELV's (Expendable Launch Vehicles). More human-rated vehicles are being developed, with the retirement of the Space Shuttles, and for a new global space race, yet these cost more than the many unmanned vehicles of today. We can learn many lessons on affordability from RLV's. DFO (Design for Operations) considers ground operations during design, development, and manufacturing - before the first flight. This is often minimized for space vehicles, but is very important. Vehicles are designed for launch and mission operations. You will not be able to do it again if it is too slow or costly to get there. Many times, technology changes faster than space products such that what is launched includes outdated features, thus reducing competitiveness. Ground operations must be considered for the full product lifecycle, from concept to retirement. Once manufactured, launch vehicles along with their payloads and launch systems require a long path of processing before launch. Initial assembly and testing always discover problems to address. A solid integration program is essential to minimize these impacts, as was seen in the Constellation Ares I-X test rocket. For RLV's, landing/recovery and post-flight turnaround activities are performed. Multi-use vehicles require reconfiguration. MRO (Maintenance, Repair, and Overhaul) must be wellplanned - even for the unplanned problems. Defect limits and standard repairs need to be in-place as well as easily added. Many routine inspections and maintenance can be like an aircraft overhaul. Modifications and technology upgrades should be expected. Another factor affecting ground operations efficiency is trending. It is essential for RLV's, and also useful for ELV's which fly the same or similar models again. Good data analysis of technical and processing performance will determine fixes and improvements needed for safety, design, and future processing. Collecting such data on new or low-frequency vehicles is a challenge. Lessons can be learned from the Space Shuttle, or even the Concorde aircraft. For all of the above topics, efficient business systems must be established for comprehensive program management and good throughput. Drawings, specifications, and manuals for an entire launch vehicle are often in different formats from multiple vendors, plus they have proprietary constraints. Nonetheless, the integration team must ensure that all data needed is compatible and visible to each appropriate team member. Ground processing systems for scheduling, tracking, problem resolution, etc. must be well laid-out. The balance between COTS (commercial off the shelf) and custom software is difficult. Multiple customers, vendors, launch sites, and landing sites add to the complexity of efficient IT (Information Technology) tools. Finally, better standards/specifications would help enable efficient ground operations. More global standards for interoperability would simplify designs and therefore their use upon assembly, launch preparation, and turnaround. Global standards for ground processing are also needed. Many sites and contractors operate differently. However, there are aspects which could make each of them more efficient if coordinated standards are agreed upon. One such example is the international S1000D specification for technical publications. It covers air, land, and sea vehicles, as well as support equipment, but it could
\end{abstract}

\footnotetext{
${ }^{1}$ Senior Engineer, Launch \& Recovery Systems, Mail Stop USK-443, AIAA Senior Member.

${ }^{2}$ Lean Six Sigma Master Black Belt, Engineering Process Integration, Mail Stop USK-321.
} 
easily be adapted to space vehicles and sites, too. We can learn from existing and past space vehicles, but we can also learn from other industries. Whether developing a new space vehicle, or looking for efficiencies with existing vehicles, ground operations is a key to affordability.

\section{Nomenclature}

\begin{tabular}{|l|l|l|l|}
\hline$A S T$ & Advanced System Technician & $M E S$ & Manufacturing Execution System \\
\hline ConOps & Concept of Operations & $M M$ & Maintenance Manuals \\
\hline$D D T \& E$ & $\begin{array}{l}\text { Design, Development, Test \& } \\
\text { Evaluation }\end{array}$ & $M R B$ & Material Review Board \\
\hline$D F M A$ & $\begin{array}{l}\text { Design for Manufacturing \& } \\
\text { Assembly }\end{array}$ & $M R O$ & Maintenance, Repair and Overhaul \\
\hline$D F S$ & Design for Support/Supportability & $N D E$ & Nondestructive Evaluation \\
\hline$D F O$ & Design for Operations/Operability & $O R S$ & Operationally Responsive Space \\
\hline$D M S M S$ & $\begin{array}{l}\text { Diminishing Manufacturing Sources } \\
\text { and Material Shortages }\end{array}$ & $O T V$ & Orbital Test Vehicle \\
\hline$D o D$ & Department of Defense & $P D M$ & Product Data Management \\
\hline$E E L V$ & Evolved Expendable Launch Vehicle & $P L C S$ & Product LifeCycle Support \\
\hline$E L V$ & Expendable Launch Vehicle & $P R A C A$ & Problem Reporting \& Corrective Action \\
\hline$E R P$ & Enterprise Resource Planning & $R \& D$ & Research \& Development \\
\hline$E T$ & External Tank & $Q D$ & Quick Disconnect \\
\hline$F R A C A S$ & $\begin{array}{l}\text { Failure Reporting, Analysis \& } \\
\text { Corrective Action System }\end{array}$ & $R B S$ & Reusable Booster System \\
\hline$F W \& T$ & Fair Wear and Tear & $R C M$ & Reliability-Centered Maintenance \\
\hline$G S E$ & Ground Support Equipment & $R L V$ & Reusable Launch Vehicle \\
\hline$I E T M$ & $\begin{array}{l}\text { Interactive Electronic Technical } \\
\text { Manuals }\end{array}$ & $R o C S$ & Roll Control System \\
\hline$I L S$ & Integrated Logistics Support & $R O I$ & Return on Investment \\
\hline$I P S$ & Integrated Product Support & $S A$ & Supportability Analysis \\
\hline$I P T$ & Integrated Project Team & $S C A P E$ & $\begin{array}{l}\text { Self Contained Atmospheric Protective } \\
\text { Ensemble }\end{array}$ \\
\hline$I S S$ & International Space Station & $S M E$ & Subject Matter Expert \\
\hline$I T L$ & Integrate, Transfer, Launch & $S R B$ & Solid Rocket Booster \\
\hline$K S C$ & Kennedy Space Center & $S T S$ & Space Transportation System \\
\hline$L M I$ & Logistics Management Information & $T P S$ & Thermal Protection System \\
\hline$L O$ & Launch Operations & $U L A$ & United Launch Alliance \\
\hline$L R U$ & Line Replaceable Unit & $U S A$ & United Space Alliance, LLC \\
\hline$L V$ & Launch Vehicle & $V A B$ & Vehicle Assembly Building \\
\hline
\end{tabular}

\section{Introduction}

Consider this interesting contrast between aircraft and space vehicle processing, described by one author at the USAF SPACECAST 2020 Symposium:

"...if airlift operations were conducted in the same manner as spacelift operations, each mission would begin with planning to determine payload characteristics well in advance of launch. The aircraft, which would be late-1950s vintage, would be selected to optimize performance based upon this payload, wasting as little performance margin as possible. Once the parts of the aircraft arrived at the airport, they would be wheeled out on the runway, one of the most expensive pieces of infrastructure, where the major components of the aircraft would be assembled and then the payload would be loaded. Since each operation is different, ground crews would have to improvise procedures for each takeoff. 
Because of the limited performance margins, any adverse weather conditions would delay takeoff. In the meantime, no other aircraft could takeoff or land on the runway. Once the aircraft was finally launched and delivered its payload, it would be scrapped. When juxtaposed in this fashion, it is clear that this approach is severely flawed and in need of major changes. ",

While aircraft and their passengers cannot be compared to space vehicles and their payloads on every point, there truly are many similarities from which the space industry can learn. Not only aircraft, but also many other industries, standards, and tools exist which can teach best practices that can apply to space. Past and current space businesses also have valuable lessons to teach. Here, we will look at what we can learn to improve ground processing.

\section{A. Global Space Market Factors}

The global space industry is going through a significant transition. Economic environments are more difficult. Space budgets are not as big as they used to be, yet nobody wants to give up access to space. There is much activity modifying or developing new space programs, launch vehicles, payloads/cargo, space stations/habitats, and launch sites. Commercial, civil, and military space are all adjusting their focus. The commercial customer market is attempting to grow, which will require worthy Return On Investment (ROI). The U.S. military is striving for Operationally Responsive Space (ORS), requiring short lifecycles from build to launch. These factors drive more need for efficiencies to save time and money. Space must be affordable and sustainable.

More Reusable Launch Vehicles (RLVs) are being developed for the gains of reusability. Expendable Launch Vehicles (ELVs ), however, are still more plentiful, and they are more cost effective until RLVs reach a high enough launch rate. More human-rated vehicles are being developed, with the retirement of the Space Shuttles, for anything from passenger tourism to International Space Station (ISS) transport to deep space exploration. Existing ELV launch sites and vehicles are going through human-rating exercises to make room for this potential market. Government regulating agencies are working with them in this. All of this typically costs more than the many unmanned vehicle programs of today. To be more versatile, many ELVs are already capable of various configurations to fit more payload customer requirements. Launch sites are striving to be more adaptable to various vehicles.

\section{B. Affordability}

All of these dynamic factors provide a challenging environment in which to become more efficient and affordable. Though budgets and schedules are changing, the need for quality and safety to provide reliability and protect human lives has not changed.

Still, if we are going to increase efficiency and profitability, we cannot continue to treat space vehicles as continuous science projects. When is the right balance for space vehicles to transition from a Research and Development (R\&D) to an operational environment and apply much needed efficiencies?

\section{Space vs. Other Industry}

How can ground processing be made more affordable? We can learn various lessons from past and current space products. We also can learn from many best practices from standards and industries outside of space.

Many topics in this paper have been discussed in arenas outside the space industry. Many good solutions have been produced. The space industry often tends to function as so specialized that outside methods or tools are either rejected, unknown, or only utilized with significant customization. In fact, some space solutions are 100 percent custom-made. While much of the hardware and software for flight, equipment, and facilities is unique to space, much of it is or could be common with other industries. Also, the methods or tools for space ground processing often do not need to be unique. In the areas of engineering, scheduling, requirements management, configuration management, product support, or Integrated Logistics Support (ILS), etc., there are many efficient, proven industry and government solutions available, which the space industry should consider applying. Analysis of the best practices can utilize industry tools such as LeanSixSigma. Some are being applied now, but the "space is too unique" and "we've always done it that way" philosophies are still active. 


\section{Ground Processing Cost}

Even in an "operational" environment, launch vehicles and most of their payloads spend the majority of their time on the ground. Once parts are fabricated, then assembly, test, integration, launch preparation, and maintenance require a large amount of time and resources before actual launch. These activities, along with launch site infrastructure, drive the cost of ground processing to be very high. Yes, design and fabrication are expensive, and efforts must continue to look for ways to lower those costs. However, the cost per pound to launch a payload also includes ground costs. Cost analysis of ground processing must start during design and development, planning for ways to lower costs for every activity up to liftoff. So, why so often is so little attention given to ground processing during development? This paper is a broad, but not comprehensive discussion of this vast subject. Some detailed analyses are included and examples given, but data sensitivity restricts how much cost or man-hour data is allowed for this affordability topic. Most content is based on experiences with the Space Shuttle and Constellation programs, with some data from other space programs. Possibly future papers can be written to cover more "ground."

\section{Ground Processing Significance}

\section{A. Definition}

We will focus on a ripe area where efficiencies can be applied - ground processing. Some would call this "ground operations," but that term also is used by those controlling a spacecraft from the ground. For this paper, we are also including assembly and integration work that many would refer to as "manufacturing operations." We are not covering fabrication of individual parts or blackbox components, and not necessarily the minor subassemblies. We begin at assembly of these because there are some similar solutions which could apply all through launch operations. The lifecycle phases covered here typically start at assembly, then test, inspection, integration, maintenance, and launch. Transportation of major elements or the entire vehicle to the launch site may occur at different points for each program. For RLVs or hybrids with partial reusable elements (e.g., first stage or booster) post-flight ground processing also includes turnaround operations, such as landing, recovery, post-flight inspection, refurbishment, overhaul, modification, and reconfiguration.

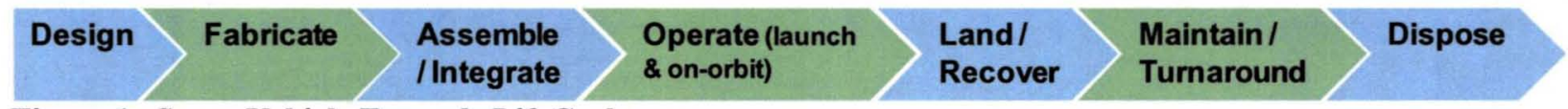

Figure 1. Space Vehicle Example LifeCycle

\section{B. Time}

In many ways, the launch facility is the remote extension of the manufacturing facility. The product is not 'finished' until pre-launch processing is complete. Pay now or pay later-where and how you accomplish these tasks should consider the most expeditious means, balanced with cost, safety, and reliability objectives. In the case where schedule time is an overriding objective, how can the process be streamlined? The U.S. Department of Defense (DoD) has been striving for ORS, which has outlined the following time goals:

Develop - to develop and deliver a new vehicle or payload within several months.

Deploy - to prepare existing launch vehicles and deploy existing payloads to orbit within days or weeks.

Employ - To launch already integrated launch vehicles and payloads within minutes or hours. ${ }^{2}$

Time is money. "The time required to complete launch-site operations is a major cost driver. If we can keep the time spent by a LV [Launch Vehicle] at the launch site short-especially on the launch pad - we can do more launches from the same site and minimize costs." ${ }^{\prime 3}$ Let us look at some typical times spent on the ground.

NASA's Launch Services Program uses a standard plan for ground processing of spacecraft at launch sites Cape Canaveral, Vandenberg, Kodiak, and Wallops. The payload arrives at the nearby payload processing facility about 11 weeks prior to launch for offline final assembly, checkout, and fueling/spin balancing. The spacecraft is then mated to the launch vehicle adapter, and then rolled out to the launch pad or final assembly building to be mated to the rocket. It will then undergo approximately 2 weeks of final checkout and closeouts prior to launch. NASA has also launched Pegasus from Kwajalein. In that case, the only difference is that the spacecraft is processed at Vandenberg, mated to the Pegasus and flown to Kwajalein encapsulated on the launch vehicle, and final launch preparation is only about a week before launch. These timelines are the standard, but are commonly tailored to accommodate specific spacecraft needs, where NASA pays for additional weeks as needed.

For Space Shuttle processing, major elements were fabricated or refurbished at various sites before being shipped to KSC for integration. Processing of each element was done in parallel, and they were interchangeable with 
multiple end items so that there were always sets being processed for the next integrated vehicle assembly. See Figure 2, where a typical landing to launch flow would take 135 to 165 days. Offline processing not shown starts when the Solid Rocket Boosters (SRB's) get recovered in the ocean and towed back to KSC by ship and lifted to land ( 1 day). Each segment spends 8 to 10 days disassembling and stripping. The 8 segments are sent by train for 21 days to the manufacturer, where segment and nozzle refurbishment and casting takes 2-3 months, depending on launch rate, before another 7-day dedicated train trip back to KSC for assembly. For an evenly spaced launch rate, you can lower costs.

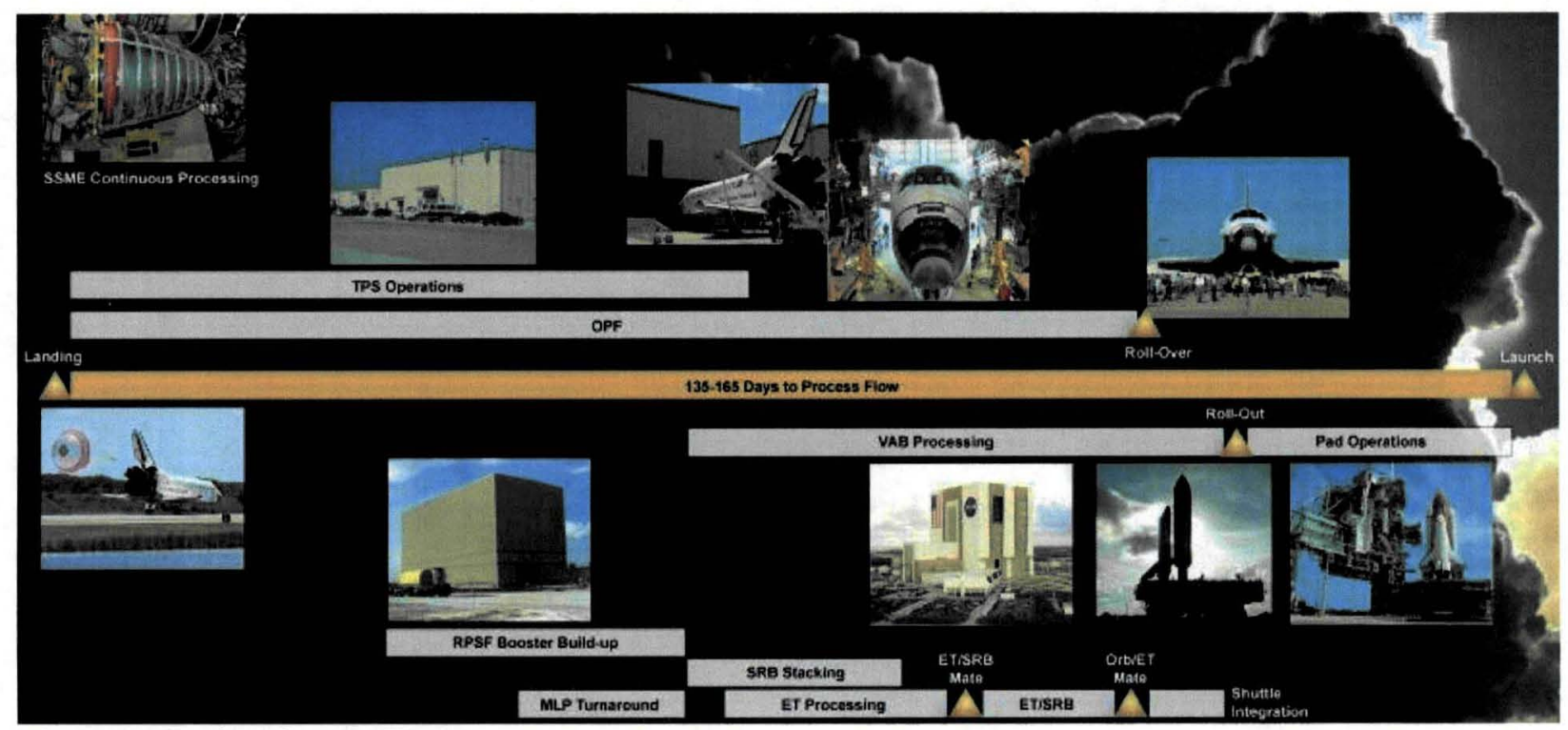

Figure 2. Typical Shuttle Flow.

A 1997 collaborative government/industry study on RLVs lists the "Number of hours for turnaround between launches (reduce)" as one of the top five priorities for key factors for design and decisions. The study found that 3-4 months is the benchmark between each launch (per individual vehicle, serial time, not labor hours), or 190,000 labor hours (direct labor hours only, Orbiter OPF only). An average of horizontal (before VAB integration) man-hours spent from missions STS-31R to STS-49 showed that 17 percent was unplanned work, 80 percent routine work, and 3 percent Orbiter modifications. (Unplanned work was higher in recent times.)This was found to correlate strongly to recurring costs, such operation of the system, and therefore to life-cycle cost and overall affordability. Their target for improvement was not an actual design feature, but rather a result of recommended design features included in the study. ${ }^{4}$

"Space Launch and Transportation Systems," a USAF- and NASA-coordinated study, presented a detailed generic example of ground processing, based on crew requirements from Delta II experience. This vehicle was chosen due to its many features common with other launch vehicles. It begins with horizontal checkout of each stage, goes through all assembly, testing, and integration, and lists all major activities up to launch. The normal processing summary time was 6 weeks, working one shift, with low overtime. The fastest time ever achieved was about half of that, with some overtime and isolated rotations to 2 nd shift. They state, however, that a new launch vehicle system designed for efficiency up front should be able to make major reductions in process time. ${ }^{3}$

We can get an idea of how ground processing requirements compare between vehicle configurations by looking at a rough estimate from an internal United Space Alliance, LLC (USA) study (Table 1) of example vehicles using KSC facilities. 
Table 1. Estimated Work Days for Example Vehicles to Launch at KSC. (Internal USA study).

\begin{tabular}{|c|c|c|c|c|c|}
\hline \multirow[b]{2}{*}{ Work Flow } & \multicolumn{5}{|c|}{ Estimated Days for Example Vehicle Configurations } \\
\hline & $\begin{array}{c}3 \text { Common } \\
\text { Booster } \\
\text { Cores, 2nd } \\
\text { Stage, Cryo } \\
\text { fuel }\end{array}$ & $\begin{array}{c}3 \text { Common } \\
\text { Booster } \\
\text { Cores, 2nd } \\
\text { Stage, RP-1 } \\
\text { fuel }\end{array}$ & $\begin{array}{c}\text { 1st Stage, } \\
\text { 2nd Stage, } 4 \\
\text { SRBs }\end{array}$ & $\begin{array}{l}\text { 1st Stage, } \\
\text { 2nd Stage }\end{array}$ & $\begin{array}{c}\text { 5-segment } \\
\text { SRB, Fwd } \\
\text { Assy, 2nd } \\
\text { Stage }\end{array}$ \\
\hline \multicolumn{6}{|c|}{ Integration - 2 shifts, with limited use of 3rd shift for SRB stacking } \\
\hline Total Integrated Flow & 20 & 20 & 24 & 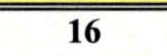 & 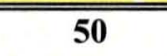 \\
\hline \multicolumn{6}{|c|}{ Pad Flow - 3 shifts per day } \\
\hline Total Pad Flow & 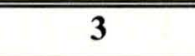 & 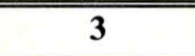 & 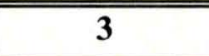 & 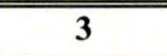 & 8 \\
\hline \multicolumn{6}{|c|}{ Facility Turnaround } \\
\hline Pad Turnaround & 20 & 10 & 5 & 5 & 30 \\
\hline MLP Turnaround & 10 & 10 & 12 & 10 & 15 \\
\hline MLP Reconfigure & 5 & 5 & 5 & 5 & 0 \\
\hline $\begin{array}{l}\text { VAB Reconfigure (after } \\
\text { launch) }\end{array}$ & 5 & 5 & 5 & 5 & 5 \\
\hline \multicolumn{6}{|c|}{ Minimum Time Between Launches } \\
\hline Same Pad, different MLP & 24 & 14 & 9 & 9 & $\mathbf{N} / \mathbf{A}$ \\
\hline $\begin{array}{lll}\text { Same vehicle type, same } \\
\text { MLP }\end{array}$ & 33 & 33 & 39 & 29 & 78 \\
\hline $\begin{array}{l}\text { Different vehicle type, same } \\
\text { MLP }\end{array}$ & 38 & 38 & 44 & 34 & $\mathbf{N} / \mathbf{A}$ \\
\hline
\end{tabular}

C. Cost

Cost is one of the most difficult aspects to compare between launch vehicles and sites. There are so many different customer-supplier programs, funding sources, primary requirements/motives (schedule, cost, safety, or reliability), and shared infrastructures that it is almost impossible to compare them evenly.

In terms of knowable costs, Shuttle is the most expensive by a wide margin, but the mission it pursues is not directly comparable, because it is manned. Pegasus and Taurus have shown great operational efficiency, an important element of cost reduction. However, the costs of component parts remain so high that both have struggled to show a profit (as of a 2005 study). Ariane and Delta have demonstrated that reliability attracts traffic, because it lowers insurance, launch operations, and other costs. Much has been invested in larger Deltas (III and IV), in the belief that traffic will command much larger payloads in much larger number. ${ }^{3}$

RLVs are expected to save money. However, there is a minimum throughput which must be reached before they are less expensive than ELVs. Shuttle's flight rate varied over the years, sometimes not launching for 2 years due to a tragic loss of life and vehicle. Reusability actually adds some costs due to significant disassembly, inspection, and refurbishment. It pays off over time since replacement vehicles do not need to be built.

Regardless of the accuracy or interpretation of the details in any cost study, it appears that, for Shuttle, at least half of the cost for "ground processing" is for infrastructure, with the remainder generally for principal processing functions. ${ }^{3}$

\section{Importance in the Lifecycle}

Figures 3 and 4 show the importance of ground operations during the in-service use or operational phase of the lifecycle. The ISO 10303-239 standard which addresses this domain is called Product LifeCycle Support (PLCS). Note that in-service use typically covers a much larger time frame than design and manufacturing. Because of this, Design for Supportability should be addressed upfront, during development. (We will discuss the similar term, "Design for Operations" later.) These graphs are more typical of reusable or long-term products. For launch vehicles, RLVs and other reusable elements would be more aligned with the "25-50 years operational life" than ELVs, yet ELVs still apply, since they repeat build, processing, and launch of the same or similar products. 


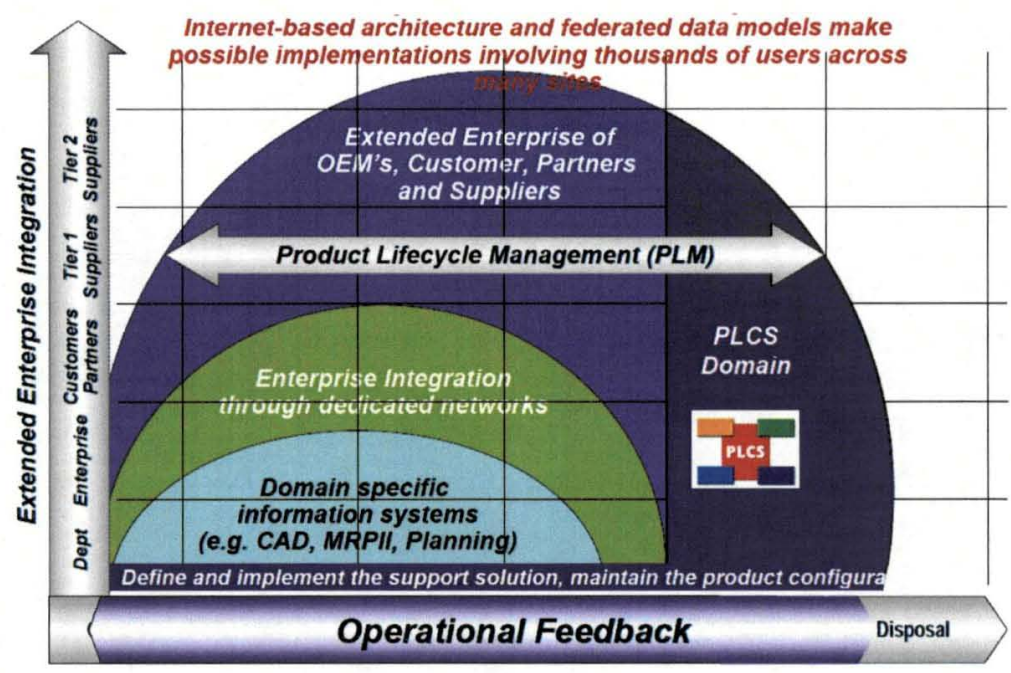

Figure 3. PLCS - Extended enterprise enabled by Internet technology (from PLCS Resources). ${ }^{5}$

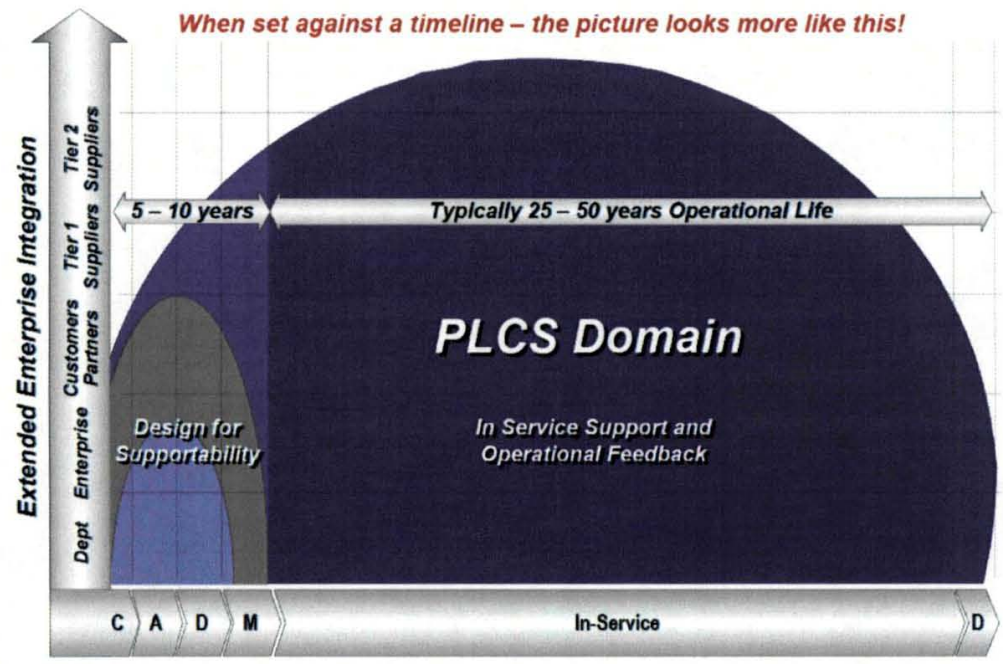

Figure 4. Importance of PLCS Over a Product's Lifecycle. 5

\section{Ground Processing by Design}

\section{A. The Need to Design with the Ground}

Use of the term "ground processing" does not mean that design is a completely separate issue. This paper does not cover design technologies or mission objectives. However, design must consider all aspects of Concept of Operations (ConOps ) during development. Designs for flight entities, support equipment, or facilities that do not consider how they will be used during processing activities on the ground can result in more challenging or costly use, or even later redesign. This was learned on numerous operational and developmental programs (space and nonspace) and in numerous studies. It is even taught in class materials. Yet, many programs later regret that they did not do it enough - or at all.

Let us dispel a popular myth: "What's good for operations is bad for development." In actuality, simpler, less hazardous design favors up-front development work: few parts, fewer drawings and specifications, fewer vendors, fewer subsystems to design and analyze, safer and fewer systems to qualify and test. 


\begin{abstract}
"The whole design has apparently been done as if hundreds of people had the time to spend weeks going over the rocket on the stand, installing valves, doing assembly work, moving cables, and generally fumbling around. Cooperation between the Test Group and [the Design Department] is lacking..."
\end{abstract}

—Gen. W. Dornberger, Peenemunde, $1941 .^{6}$

Various terms in this section have the same overlapping concept: Design for Manufacturing and Assembly (DFMA), Design for Operations, or Design for Operability (DFO), and Design for Support, or Design for Supportability (DFS). All of these highlight the need for input into the design/development phase by personnel and data from downstream ground processes.

Manufacturing can be defined as everything from machining new metal parts to full product assembly, but we are focusing only on the assembly aspects here. Operations are those activities where people, equipment, and materials interact with the flight vehicle and the payload and flight crew in a set of processes that produce an acceptably safe flight. The support infrastructure (whose extent and complexity are driven by the nature of the operations) includes the accumulated facilities, equipment, workforces, and outsourced services needed to conduct the operations. ${ }^{3}$

\title{
B. Design for Manufacturing and Assembly
}

DFMA generates an environment where a cross-functional team works together to optimize the design for cost effective manufacturing. Considerations often associated with DFMA, such as reducing the number of parts and employing rapid assembly methods such as self-locating features with fewer fasteners, yield efficiencies with every build-up. ${ }^{?}$

In one example from Ares I-X, the Solid Rocket Booster (SRB) modifications included the addition of Booster Deceleration Motors and Booster Tumble Motors on the first stage structure. The precise positioning of the frames with extremely tight tolerances on the structure required elaborate tooling, alignment fixtures, and a considerable amount of time. This one of a kind modification for the test flight was successful. However, it illustrates how utilizing self-locating design features could simplify the build-up in the eventual design, had DFMA been fully implemented.

\section{Design for Operations/Operability}

Roughly 85 percent of lifecycle operating and support costs will be determined as soon as requirements are set early in the life of a program. DFO identifies operations and supportability considerations and trade-offs early and throughout the Design, Development, Test and Evaluation (DDT\&E) phase, thus significantly contributing to total system performance and lifecycle cost reduction, which is critical to a project's success.

One author defines a subset of DFO, Designing for Launch Operations, as “...designing the new SLaTS [Space and Launch Transportation System] together with all operations that facilitate its field processing and launch. The process of designing for launch is a subset of the process of designing the new vehicle system to meet new objectives. This vehicle design must include all the means to carry out these operations. Therefore SLaTS design, when best done, includes design of the launch architecture, its team and its methods, selection of the launch site, design of ground support equipment (GSE), logistics planning, and architecture of facilities that house, implement, and protect the launching processes, personnel, and surrounds. This means that the designers of the launch operations (LO) process must educate the LV [Launch Vehicle] design team in realities of LO work." 3

Human factors are more significant than many people realize, and this is one aspect which factors into DFO. Based on Shuttle and Constellation experience, USA is working on Human Engineering Modeling and Performance efforts for next generation spacecraft programs. They are developing a Human Factors Innovative Tool to examine human, machine, and environment interfaces for incorporation into DDT\&E. This will optimize designs, operations, planning, and training, providing risk and cost reductions.

\section{Design for Support/Supportability}

As shown in Figures 3 and 4, the largest timeline in a lifecycle is typically the in-service operations and support. So, the most cost and time gains will be realized by designing for them. (Again, this applies more substantially to RLVs, but it still applies to ELVs.) This sounds simple enough - yet we are prone to do just the opposite. The easy way out for the designer and the operator is to only "support the design." A more proactive, structured, and ultimately more economical approach is to "Design for Support." ${ }^{3}$ Table 2 shows an example approach to DFS. 
Table 2. Design for Support Sample Process ${ }^{3}$

\begin{tabular}{|l|l|}
\hline \multicolumn{1}{|c|}{ DFS Step } & \multicolumn{1}{c|}{ Step Description } \\
\hline $\begin{array}{l}\text { 1. Understand requirements, } \\
\text { objectives, and constraints }\end{array}$ & $\begin{array}{l}\text { A. Review requirements of the enterprise and the launch system } \\
\text { specification } \\
\text { B. Ensure operational requirements, particularly flight rate and } \\
\text { recurring cost objectives, are understood } \\
\text { C. Set up requirements trade matrix }\end{array}$ \\
\hline $\begin{array}{l}\text { 2. Create a Top-Level, Preliminary, } \\
\text { Concept of Operations (ConOps) }\end{array}$ & $\begin{array}{l}\text { A. Organize a template of generic operations and infrastructure } \\
\text { functional possibilities }\end{array}$ \\
\hline $\begin{array}{l}\text { 3. Create a ConOps by identifying } \\
\text { functions to be performed and } \\
\text { options to perform them }\end{array}$ & $\begin{array}{l}\text { A. Set up a functional definition matrix for concepts of operations to be } \\
\text { traded }\end{array}$ \\
\hline $\begin{array}{l}\text { 4. Estimate lifecycle characteristics } \\
\text { and resources }\end{array}$ & $\begin{array}{l}\text { A. Estimate capital investments and recurring annual costs } \\
\text { B. Estimate flight rate capability, throughput performance, and ground } \\
\text { safety characteristics } \\
\text { C. Build cost-performance curve }\end{array}$ \\
\hline 5. Document and iterate & $\begin{array}{l}\text { A. Launch system specification } \\
\text { B. Requirements trade matrix for operations }\end{array}$
\end{tabular}

DFS does not stop with the design phase. After you Design for Support, you then Support the Design as you go through the lifecycle phases. Along the way, you provide feedback to the design process to iteratively improve the design further. Figure 5 demonstrates this.

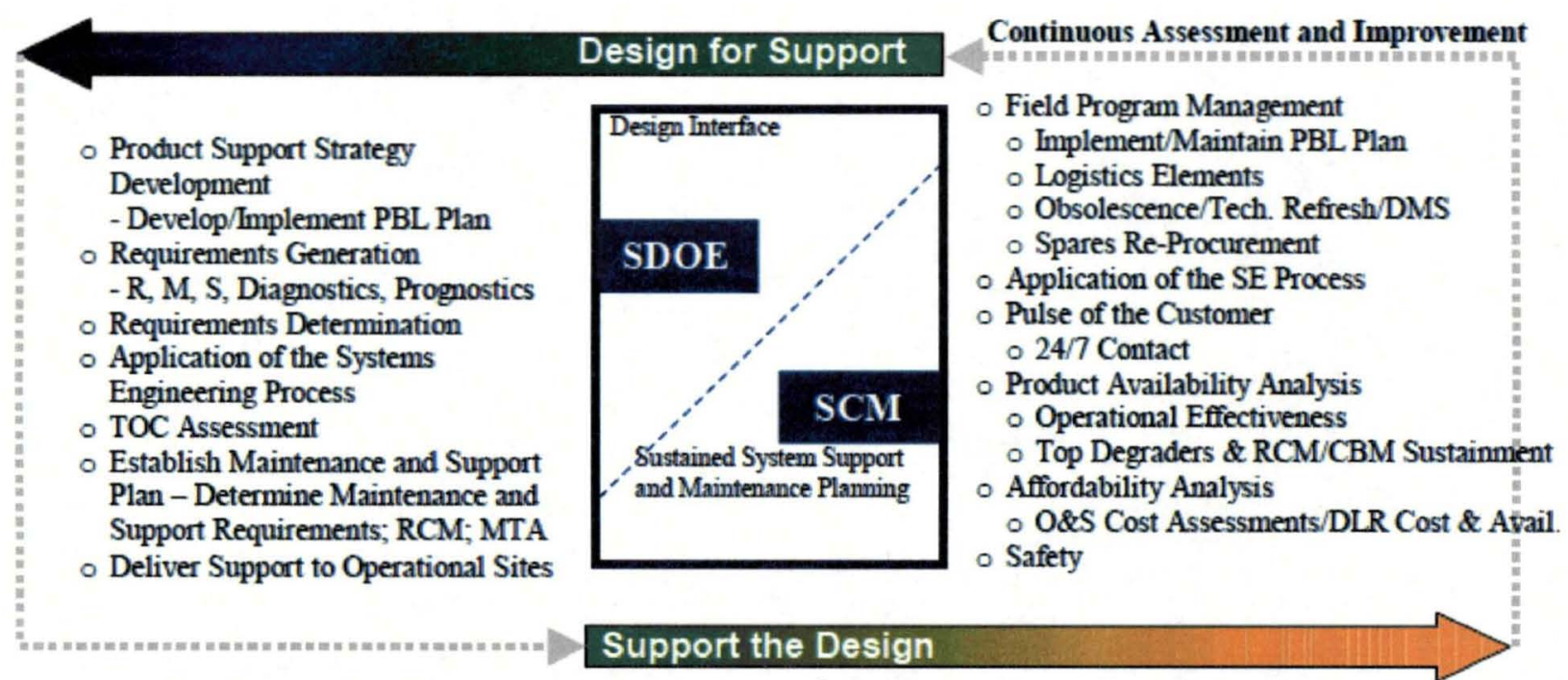

Figure 5. 'Design for Support' and 'Support the Design'.

(SDOE = System Design for Operational Effectiveness, $S C M=$ Supply Chain Management)

DFS is so significant to the U.S. and U.K. militaries, that they mandate it within the concept of Integrated Logistics Support (ILS) / Integrated Product Support (IPS). Its purpose includes DFS throughout the lifecycle. Even then, one article says, "Acquisition processes pay too little attention to supportability and consistently trade downstream sustainability for required capability or program survival. Some program managers assert that logistics is their only discretionary account, making it a frequent target for inevitable resource reductions." ${ }^{9}$ We will discuss ILS/IPS later.

Diminishing Manufacturing Sources and Material Shortages (DMSMS) is another significant DFS point needing consideration. This common industry problem can be worse for the space industry, since more specialized parts, materials, and processes are used, and suppliers do not continue with these. 


\section{E. Lessons Learned Examples}

"To illustrate the importance of designing for operability and supportability, Figure 6 shows the original vision of simple and responsive turnaround operations for the Space Shuttle orbiter in an early program rendering [NASA Kennedy Space Center Archives, 1974]. By 1981, the hardware became operational, and the simplicity had eroded. Also eroded were the flight rate expectations, which had originally been 40 flights per year from the Kennedy Space Center [KSC] in Florida and 20 flights per year out of Vandenberg Air Force Base [VAFB] in California [Huether, McCleskey, Rhodes, 1995]... [Various] factors...have led to a very complicated and intrusive turnaround operation fraught with a high degree of unplanned work to replace over 100 flight components and over 700 ground supportequipment components." 3
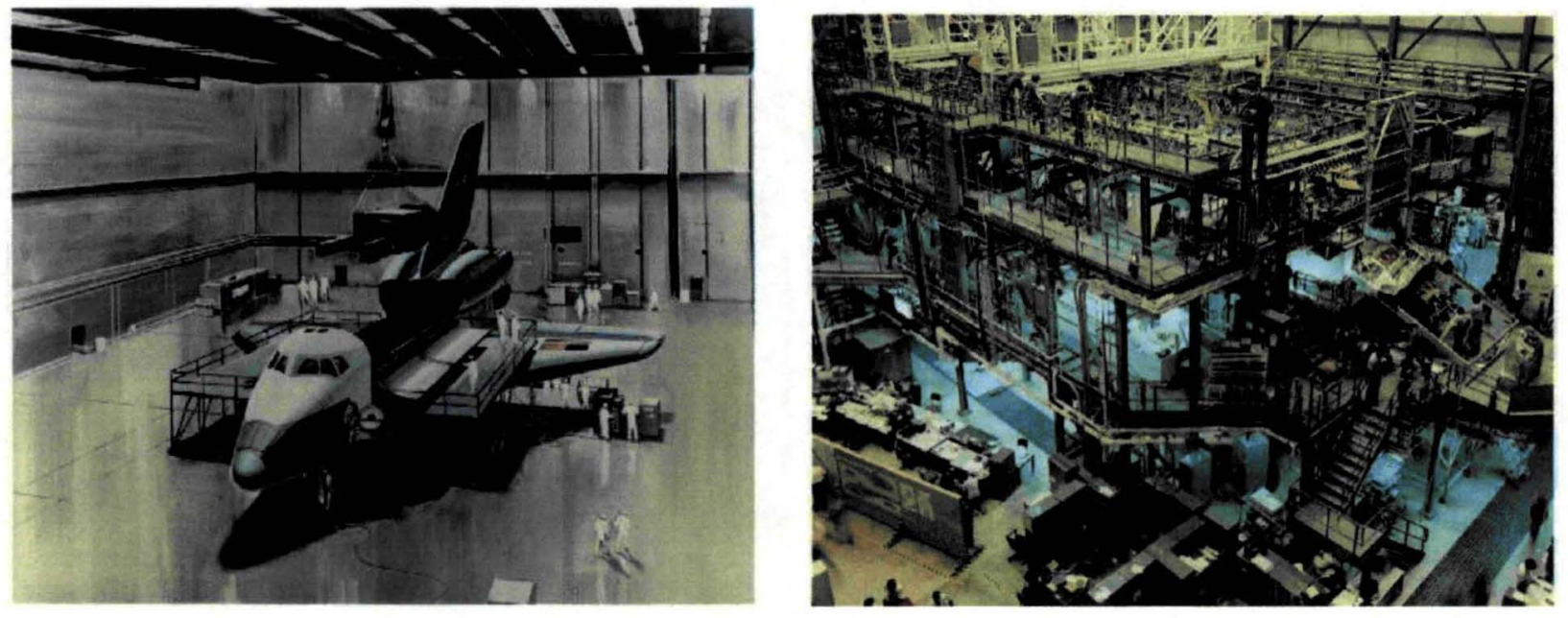

Figure 6. Original Orbiter processing concept vs. design reality.

One example where operations were not properly considered on the Space Shuttle caused multiple hazardous incidents. Hypergolic propulsion, which uses a toxic fuel and oxidizer combination, was used in various Shuttle systems. Quick disconnects (QDs) for each liquid were located near one another on an interface panel with the same size fittings. When servicing, technicians used various visual techniques and procedures to prevent unintentional cross connection. To avoid such incidents, the design team could have been made aware of the potential hazardous errors by operations input, and they could have made minor design changes to mistake-proof the connections, using different shapes or sizes. 


\section{Ground Processing Flow Efficiencies}

Now that we have addressed upfront design, what can be done to streamline operations in the process flow? An industry standard tool available like Lean6Sigma can analyze and find solutions, conquering inherent complexities.

\section{A. Shuttle Processing - Best Lessons Learned}

With Shuttle recently ended, there have been opportunities to review lessons learned from 30 years of operation. Here is a list of the most significant of those lessons applicable to developing/future programs, compiled by USA and NASA, many of which apply to subsequent sections of this paper:

1. Baseline requirements prior to the start of the processing flow and be very selective about adding requirements

- Late requirements can negatively impact cost \& schedule and the ability to meet milestones

- Understand the impacts to the basic, or standard, turnaround flow critical path

- Only add requirements that affect safety and/or mission success

2. When discrepancies arise, only fix what needs to be fixed to ensure crew/vehicle safety and mission success (i.e. Do not polish the apple)

- Any work performed on the vehicle brings with it a risk of collateral damage (i.e. What seems like a small task could lead to a larger scale job that impacts the schedule)

- Establish a robust constraints management process to deal with unplanned work

- All work has a price tag associated with it. Do not spend resources unnecessarily

3. Schedule stability is key (minimize work stoppages and rescheduling)

- Minimize added work (see \#1 and \#2 above)

- Ensure resources are ready and available (people/paper/parts)

- Thoroughly track facility PMs and support equipment calibration to ensure equipment is ready when needed

- Allocate contingency time throughout the processing flow to help absorb unplanned work

4. Have the design team co-located at the processing site when hardware processing is occurring

- Cross-country time delays negatively impacts the schedule

- If co-location is not possible, sync the work time periods of both locations to ensure support is available when needed

5. Document requirements

- If it is a requirement, it should be documented ahead of time (i.e. do not develop requirements as you go)

- Make sure the requirements are clear and concise

- Use a range of acceptable values if possible

- Strong requirements facilitate timely resolutions when problems arise

\section{B. Manufacturing Assembly Operations}

Launch vehicle programs can perform major assembly and integration in a few different ways:

1. Perform some at manufacturing site, transport to finish at launch site assembly building, then transport ready to launch pad.

2. Transport all major elements to launch site, and perform all at launch pad.

3. Do some hybrid of these two.

We consider manufacturing assembly operations as one type of ground processing. "The integrate-transferlaunch (ITL) concept was developed to minimize time spent on the launch pad. In this concept, vehicle-payload integration occurs in a separate facility, usually in the vertical orientation. Then, when it is ready to launch, we transport the assembled vertical stack to the pad, run last-minute checks, and launch the vehicle. The pad is then clear for the next stack, which may be assembled in the same or a different facility. At the opposite extreme is the approach of erecting, assembling, and checking the vehicle and payload on the launch pad. This approach has the disadvantage that, in the event of a problem with the vehicle or payload, the pad is not available for another vehicle's launch without the major operation of removing the ailing stack from the pad. Some large, complex vehicles have spent more than a year on the pad before launch, in part due to payload or LV problems." ${ }^{3}$ 
"System design can produce higher efficiency by using horizontal integration, as Russian launch operations have demonstrated. Their augmentation motors are liquid-fueled, thus light enough (with proper GSE strongback design) to test, integrate, then retest while integrated, all elements of the LV with payload and fairing included. To the extent future LV system design can permit manufacture near a chosen launch site, integration of stages and elements horizontally on an erector at the factory, then short transport to the launch locale, fueling and launch, we can confidently reduce and make the past extensive efforts at launch site integration more efficient." 3

SpaceX, their competitors, and various analysts have commented on the benefits of their unique approach to developing a space launch system. Most larger companies have a huge supply chain, which can get problematic and expensive. Counterfeit parts are a huge issue. SpaceX has strived to manage their own supplier base, building most items themselves. Most (well over 90 percent by part count, mass, and volume) of Falcon 1 and Falcon 9 launch vehicles, the Dragon spacecraft, and associated ground systems are all designed, manufactured, tested and operated internally. "In general, it is considered preferable to spend more (even double) the cost to develop a capability inhouse than to pay an external entity, since it allows control over the cost, schedule and quality." ${ }^{10}$ This also avoids counterfeit parts and diminishing supplier issues throughout the lifecycle.

\section{Integration and Testing}

Whether at the manufacturing site or launch site, much integration and testing is required for full assembly. Problems are always encountered during assembly and test. A solid integration program is essential to minimize these impacts. Integration not only ensures fully functional systems to ensure mission success, but it also coordinates requirements and issues to prevent or minimize delays. Without it, preventable issues will arise and cause the need for rework, repair, additional inspection or testing, and possible requirements violations or negative customer reviews. All of these cost resources, schedule time, and labor hours which could have been avoided with an investment in integration.

Integration has many elements with interfaces, typically:

- Internal Element Integration: Vehicle, payload, booster, other (e.g., External Tank)

- Element-to-Element

- Payload/Cargo-to-Vehicle

- Element-to-Ground structure

- Element to Ground transport vehicle

\section{Testing}

Fit-checks and alignment pinning are used to test structural elements before assembly. Results are immediately visible. For systems, however, other methods must often be used to test and see results. Facility control panels, GSE, gages, instrumentation, etc., are connected to flight hardware to verify correct function, monitor operations, and measure performance. Testing is critical to verify proper integration and operation of electrical, fluid, and mechanical systems. Systems need test/checkout to ensure reliability; however, unnecessary testing is sometimes performed, increasing schedule and cost. On-orbit performance should be a consideration to use to validate systems and reduce ground testing. A reliability-centered maintenance (RCM) program can aid in determining when testing is truly necessary to avoid excess.

\section{Multi-contractor or Multi-element vehicles}

Integration is even more challenging for multi-contractor or multi-element vehicles. Many mistakenly think of the Space Shuttle solely as the airplane-like vehicle that flies back to Earth. The Shuttle [also called the Space Transportation System (STS)] is actually the integration of three major elements: the Orbiter (airplane-like), the External Tank (ET), and the two Solid Rocket Boosters (SRB). The Orbiter was designed and manufactured by Rockwell (now Boeing), the ET by Martin Marietta (now Lockheed-Martin), and the SRBs by Thiokol (now ATK). The Orbiter itself is an integration feat, having many sections, components, and systems designed and built by various suppliers to Rockwell. The SRBs were built by Thiokol (now ATK), but the local KSC SRB depot handled disassembly, refurbishment, and reassembly, which included some manufacturing of replacement parts. Also, the local SRB depot processing contractor (USBI originally, which became part of USA) had design responsibility over the forward and aft sections. Each Shuttle element had its own integration department. Then, USA, the prime Shuttle contractor at $\mathrm{KSC}$, had to not only manage the individual element integrations, but also integrate the integrators.

USA's Shuttle integration experience helped resolve difficult issues in many examples for the Constellation program's Ares I-X test rocket. For example, hypergolic servicing of the Roll Control System (RoCS) modules for Ares I-X was accomplished offline to minimize impacts. While servicing took about 2 days to perform offline, this 
was completely parallel to other vehicle processing. It also allowed hazardous SCAPE operations to be performed at ground level rather than 200 feet up at the launch pad with limited access. This not only saved expensive pad modifications, it also allowed the area to be closed out for flight before rollout to the pad. This reduced the pad flow and overall vehicle processing time by about 3 days. Between eliminating pad modifications and shortening the overall program by 3 days, the net cost savings is estimated to have been over one million dollars. The electronic Manufacturing Execution System's (MES) enabled visibility of the test execution progress, down to the operation and step, in near real-time. The information assisted technical planning and management decision making. The MES also enabled resolution of problems with changes implemented and approved in minutes versus the traditional paper process taking hours and severely interrupting the task execution.

\section{Launch Operations}

Once a launch vehicle is complete and its payload is loaded, launching is not as simple as fueling and igniting. These are hazardous and expensive assets, and a human crew is on some of them, so they must be handled with the utmost care. We have talked about many activities necessary to get to this point. Now it is time to load fuel, ready the control team in the launch control center and configure controls for flight, activate the range(s), establish local emergency contingencies, ensure remote landing site readiness for returnable vehicles, deploy recovery vehicles if reusable elements exist, send out weather and security monitors, ingress the flight crew if using a human-rated vehicle, and begin countdown. Testing truly never stops-it just continues during launch operations, to make sure all is still well.

\section{Launch Countdown Delays}

Unfortunately, issues do occur during this phase (fortunate that they are discovered before launch). Nobody likes launch delays, but everybody wants a successful mission. The causes of launch delays indicate where efforts could be focused to more efficiently resolve the causing issues, and evaluate how to possibly prevent them. Over 45 percent of all delays require ground resolution, as shown in Figure 7. If the launch team in the launch control center or the management team cannot resolve or accept the issue, then ground operations crews are sent out to investigate and repair on the pad. Rapid response is essential, yet with the utmost quality and safety. Launch delay time comes at a great cost. 

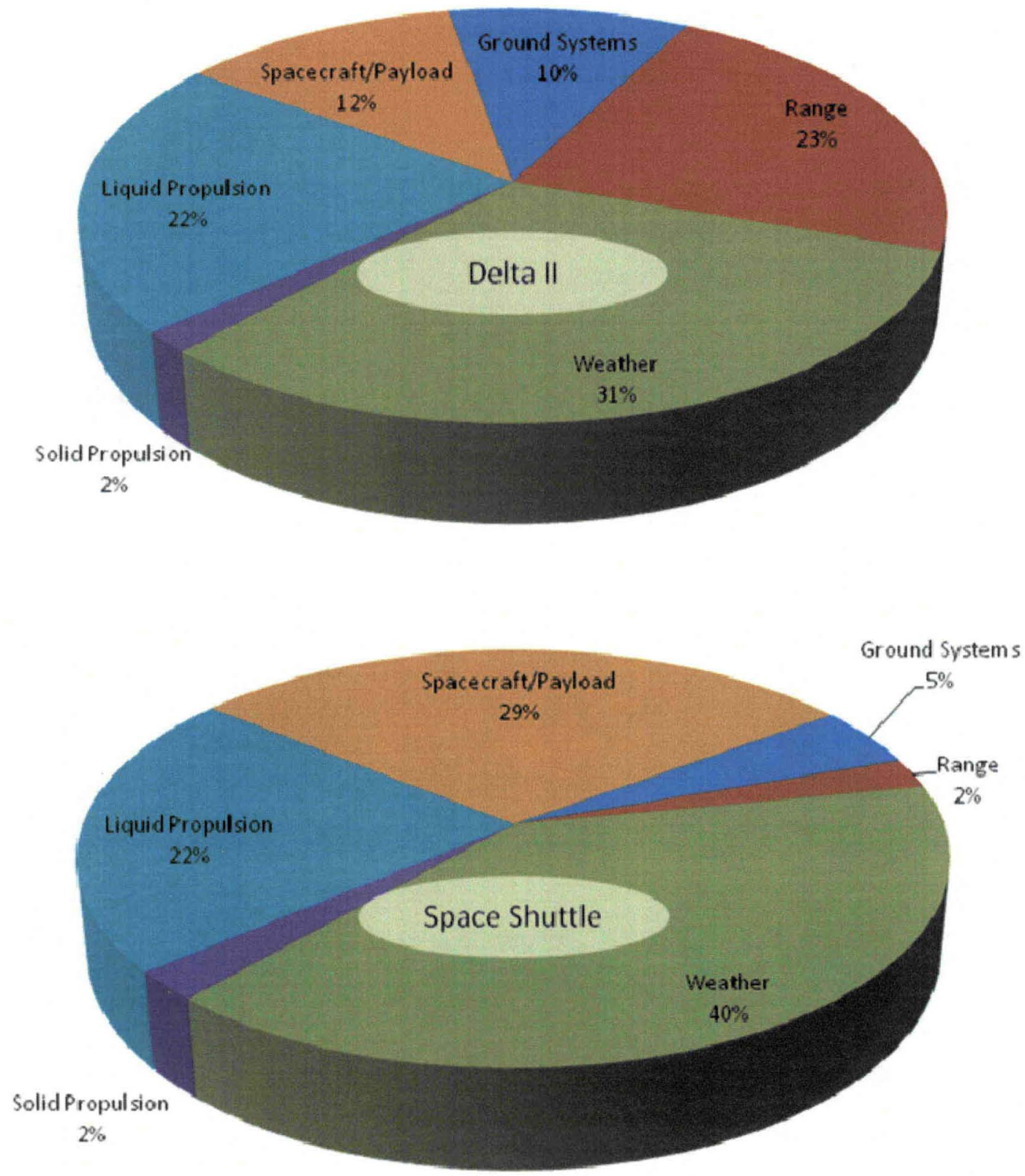

Figure 7. Example Sources of Launch Delay. ${ }^{11}$ 


\section{DFO for Easy LRU Access}

One DFO concept that would aid countdown issue responses is to design more problematic Line Replaceable Units (LRUs) for easy access to repair or replace. Many systems require removal of multiple LRUs before the defective LRU is accessible. Defining which LRUs are more likely to fail or more difficult to access should have been determined early during logistics analyses. Minimal access, removal, and installation times could save huge cost, schedule, and customer satisfaction hits during launch operations. This is also a factor needed for the ORS concept. ${ }^{2}$ This same DFO concept would obviously reduce time and cost during all prior ground processing, too.

\section{E. Post-Flight Operations}

Landing, recovery, and/or post-flight turnaround activities are performed for returnable or reusable vehicle systems. So far, only a few space vehicles have been returnable to land on Earth, and ever fewer of those were reusable. Human space capsules are returnable, but so far have not been reusable. RLVs include X-15, NASA's Space Shuttle, and SpaceShipOne. The former Soviet Union's unmanned Buran space shuttle flew in 1988, but after its only flight, it was found not feasible to reuse, and its program cancelled. In 2010, the Orbital Test Vehicle (OTV), also known as the X-37, was a vehicle carried as an unmanned payload aboard an Atlas V (not exactly an "RLV"). It was not the launch vehicle, but it returned after 224 days in orbit, making an autonomous runway landing. More returnable or reusable vehicles are in development. These must address many more recurring situations than ELVs, which is a key to finding cost and time savings. ELVs can learn from these, since less trend data can make it harder to find the best places to invest in efficiencies.

\section{Recovery}

Recovery operations for reusable booster or stage elements are typically performed in the ocean. To date, only Shuttle and Ares I-X have had the only successful reusable boosters. Falcon 9 is developing this capability but had limited success on their test flight. The U.S. Air Force is pursuing an effort to develop a Reusable Booster System (RBS) to replace the existing Evolved Expendable Launch Vehicles (EELV) beyond 2025, and aims to cut launch costs by 50 percent by combining a reusable first stage with expendable upper stages. The booster would take off vertically and return to a runway landing at the launch site. ${ }^{12}$

Recovery is not performed often, and its crews are very specialized. To avoid unproductive downtimes, and to provide better teaming and hardware familiarization, a multi-functional team should be assigned, so that these crews also participate in work like disassembly and refurbishment.

\section{Landing}

Landing for returnable vehicles has many factors which affect affordability. Ideal conditions, of course, are to land at the site where turnaround maintenance will be performed. For the Orbiter, this was also the launch siteeven more ideal. However, conditions sometimes dictate alternate landing sites. It should be noted that each alternate landing site which is manned or maintains facilities and equipment will add significant time and cost. Also, any conditions different from the prime landing site should be evaluated for impacts. The Orbiter landed at White Sands Test Facility only once. It never got all the fine gypsum sand out of the crevices, so it was documented many times as a nonconformance suspecting corrosion during borescope inspection.

\section{Turnaround}

After recovery or landing, many actions are needed to get the vehicle back in-flow: Crew egress, post-flight evaluations, deservicing, and payload/cargo removal, if required. Multi-use vehicles then require reconfiguration. Payload interfaces and procedures should be standardized as much as possible to avoid writing new procedures each flow.

\section{F. Maintenance, Repair, and Overhaul (MRO)}

MRO work is one area in which the Shuttle exercised extensively, while ELVs have minimal (by comparison) maintenance and repair, most often at the manufacturing plant, and no overhauls. As was stated previously, the Shuttle launch site was uniquely established in every part of the lifecycle, from design to manufacturing, operation, return, and turnaround MRO. Many common techniques and tools have been utilized across the lifecycle. Here, we will focus on the unplanned maintenance and repair, and on overhaul tasks, whether done during the process flow or at depots.

"The entire Shuttle refurbishment process and related facilities are complex, critical, expensive, and time consuming. However, we replace only the external tank and selected smaller components for every flight. The design lifetime of each Orbiter is 100 flights. Designers have created less complex reusable vehicles that require far 
less rework between flights. The experimental Delta Clipper, for example, flew several times in a few months with minimal turnaround time and effort." ${ }^{3}$

\section{Nonconformances and Resolution}

MRO must be well-planned - even for unplanned problems. One weakness early in the Shuttle program was a lack of sufficient planning for unexpected issues. Planned maintenance and even overhaul work was thoroughly addressed, but schedules did not always have enough time built-in for resolution of nonconformances, also called failures, defects, anomalies, discrepancies, problems, or issues. Figure 8 shows the high count of nonconformances each flow on an Orbiter.

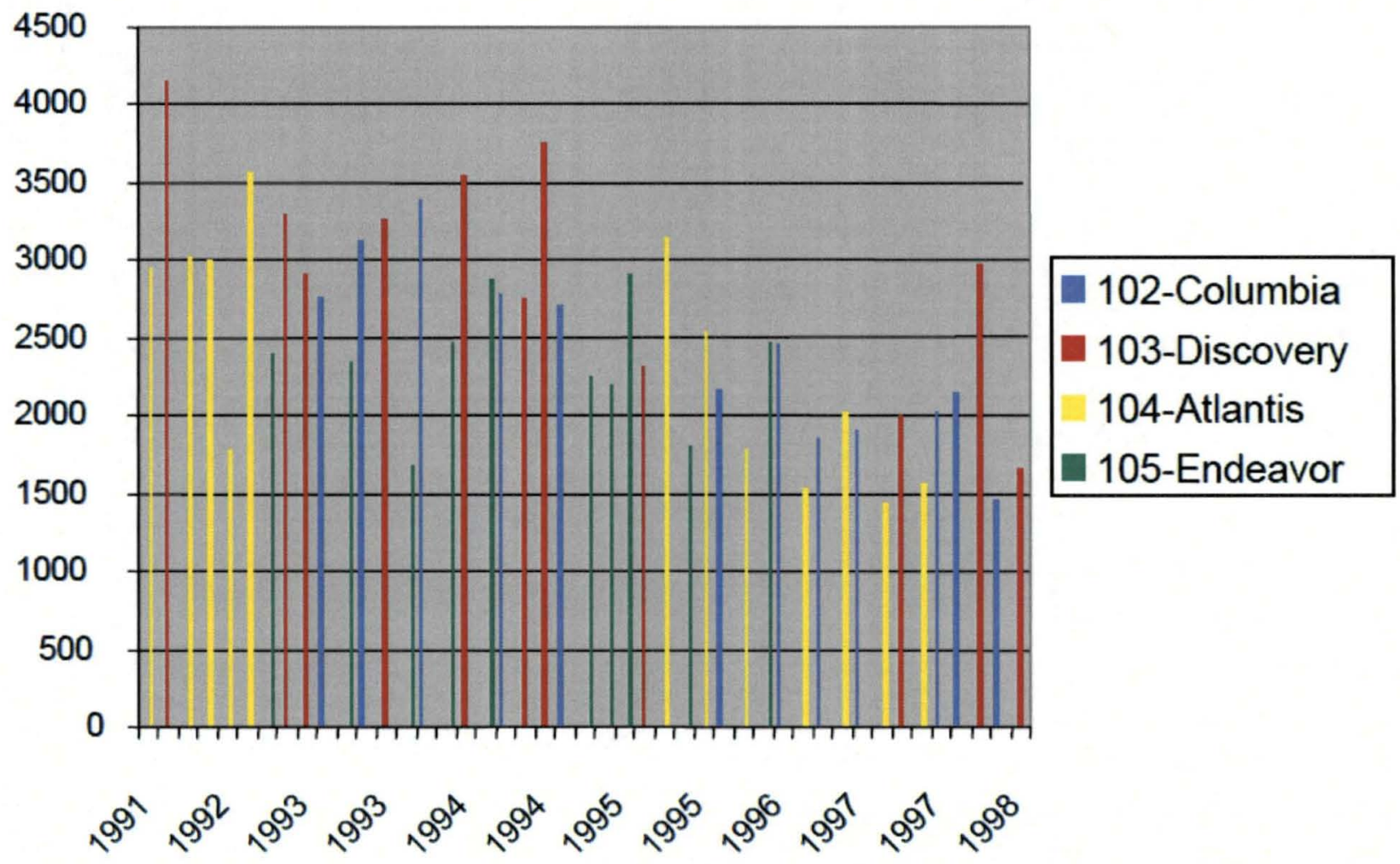

Figure 8. Sample History of Shuttle Nonconformance Problem Reports. ${ }^{13}$

Eventually, after many smatterings of problems needing resolution, the flow managers, planners, and schedulers began planning time for nonconformances. Shuttle nonconformances were handled by the Problem Reporting and Corrective Action (PRACA) system, later renamed iPRACA by its new IT toolset. The common industry term is Failure Reporting, Analysis and Corrective Actions System (FRACAS). Such a system is not only for immediate fixes of broken LRUs, but also should be used for reliability and safety. As a tool to determine root causes and corrective actions, this can prevent or minimize repeated nonconformances, saving cost and time.

Allowable defect limits are also required to withstand nonconformances. Shuttle had some allowable defects documented, also called Fair Wear and Tear (FW\&T). For example, a minor dent of 0.002-inch maximum depth was allowed in specific metal parts. However, most limits were very conservative, very scarce, and not easily found or applied consistently — even within the same element (especially the Orbiter). The issue was often magnified due to repair or replacement being unfeasible, which drove design analysis to accept or repair with the extensive Material Review Board (MRB) approval. Improvements were made over time, but it never got to the fully operational level like an established aircraft model. Limited progress is understandable for a developmental space vehicle, but more attention should have been given to defect limits during design and throughout the lifecycle. Sufficient defect limits need to be in-place as well as easily added during manufacturing and operation phases. This is another DFO candidate. 
Standard rework and repair procedures need to be in-place, as well as easily added. Rework in response to a nonconformance is corrective action to return the hardware to design condition (per drawing, specification, or other approved document). Paint touch-up, wire clamp adjustment, or fastener replacement are examples of standard rework procedures that should be available. More than that, more substantial standard rework procedures like LRU replacements, should be available if common enough or if time-critical for potential countdown situations. Troubleshooting or test is another type of procedure that could be considered rework. Many of these should be available if common or time-critical. If the issue cannot be reworked, but requires action that deviates from the design condition, then a repair is required. Again, certain standard, preapproved repairs should be made available for processing needs. Since these would need a higher level of approval, and since the hardware will be left asmaintained rather than as-designed or as-built, careful analysis should be made to determine which repairs are most needed. Either rework or repair that is not in a preapproved procedure will require a unique instance of authoring disposition, subject to appropriate approvals, publishing, and scheduling. This is obviously more labor intensive and can be very costly with numerous or lengthy nonconformance situations. In the aircraft and other industries, these are included in standard Interactive Electronic Technical Manuals (IETMs) or older style paper Maintenance Manuals (MMs). Having standard procedures ready to respond to issues enable savings by quick resolution.

Authorization of rework or repair is another key to efficient MRO. Aircraft typically have comprehensive IETMs or MM sets that cover all systems, structures, and general situations such as hardware lifts, offloading, and Nondestructive Evaluation (NDE). If a nonconformance is covered within the limits of the IETM, the technician is authorized to initiate IETM procedures. Once outside such limits, they contact engineering for resolution. The aircraft industry typically needs engineering in a minimal number of situations, around 5 percent to 10 Percent. The Shuttle used engineers for the majority of nonconformance resolutions, approximately 80 percent to 90 percent of the time, for several reasons: lack of allowable defect limits, too few preapproved rework and repair procedures, and maintenance philosophy that determined that the Shuttle was too unique to leave many decisions to technicians without engineering involvement. An effort was made to shift more responsibility to technicians and reduce engineering time involved, called the Advanced System Technician (AST) program. High-performance technicians were allowed to go through much of the engineering training and obtain authority to initiate more procedures and even author some unique dispositions. This, coupled with efforts on FW\&T and preapproved procedures, improved processing some, but each effort never went far enough before Shuttle cancellation was announced. Had a more comprehensive FRACAS been established in the beginning, it would not have been so difficult to make-up lost ground. Before the attempt for all systems to shift from engineer to more technician, actually in the early Shuttle years, there was one area which gained much efficiency envied by others - the Orbiter's Thermal Protection System (TPS). This TPS (as opposed to SRB or ET TPS) is defined as the hundreds of tiles and blanket-like insulation bonded to the external skin, providing aerodynamic flow as well as protection from superheated reentry conditions. Numerous tiles were found either fallen off (debonded) or chipped during post-flight inspections. Action had to be taken quickly to learn how to handle numerous and critical nonconformances on this newly developed RLV. The TPS designers and processing personnel resolved the most critical issues yet learned that the "system" of tiles, probably the most fragile critical Orbiter parts, would have the highest number of nonconformances after each flight. By necessity, this drove an entire system of FW\&T, standard procedures, and technician authorization which became a well-oiled machine.

What causes so many nonconformances? In the case of the Orbiter, external impacts damage, TPS, windows, and payload bay surfaces exposed while doors are open. Internal crew module damages can be caused by the crew. Some component failures occur during in-flight use. Environmental conditions can seep into many corners and cause things like corrosion-especially at an oceanside launch site. However, a large percentage of nonconformances were "ground-induced," or collateral damage. The mere presence of numerous personnel performing many activities with numerous pieces of equipment is a combination ripe for unintentional damage and wear-out during ground maintenance or testing. If you reduce the activity and personnel access, you will reduce nonconformances. Again, such reduction needs to be validated by analyses.

\section{Overhauls and Upgrades}

Overhauls are typically scheduled time to take a vehicle offline to do unusual, significant maintenance and modifications. Many RLV routine inspections and maintenance can be like an aircraft overhaul. Though the Shuttle operated for 30 years, it still functioned with a very low usage frequency and was treated more like an R\&D project in development. The Shuttle operated under more rigorous conditions and had more risk than a typical Earth-flight aircraft. There was definitely good reason for more extensive maintenance. However, this is yet another opportunity for improvement. After 30 years and 135 flights, enough trend data should have been available to analyze where 
maintenance could have been reduced. Good risk management, logistics analysis, safety, and quality programs should keep things in check to prevent unsafe reductions.

The Shuttle Orbiter version of an overhaul would typically occur every 8 flights and bring it offline for one to two years. (The flight rate was only one to two per year for each Orbiter.) Most Orbiter Maintenance Down Periods were done at Boeing's Palmdale, California facility, where Rockwell originally manufactured the Shuttles, but a few were done at KSC by prime operating contractor USA. The inspections were very invasive. That said, similar to operational inspections, nonconformances will increase with more personnel access and maintenance activity.

Reusable boosters or first stages understandably require extensive, overhaul-like maintenance, since they require disassembly and refurbishment after each use. Also, the only reusable boosters so far have fallen into the ocean, and such impact tends to necessitate more significant maintenance. Fly-back boosters are in development, which would greatly reduce maintenance needed post-flight, since they would avoid impact and salt water. If the design and manufacturing costs can justify it, ground processing costs would definitely be reduced.

Modifications and technology upgrades should be expected. Some performance issues or enhancements will require engineering changes which result in modifying the vehicle. Many times, technology changes faster than space products such that what is launched includes outdated features, reducing competitiveness. Hardware or software upgrades are then considered. Most such upgrades are typically scheduled during overhaul period, and more urgent safety or mission modifications are done during normal processing between flights. However, since RLVs spend so much time on the ground after each flight, the temptation to incorporate more non-urgent upgrades is hard to resist. This drives longer schedules and higher cost for what should be quick turnaround for objectives like ORS or commercial ventures. An R\&D mindset will also cost more by keeping a larger design team onboard than what is needed for routine flights. It may be best to fund and schedule upgrade efforts separately.

\section{G. Special Transportation}

Most manufacturing or assembly of vehicles and payloads is not done at or near launch sites. In fact, they are usually done so far away that transporting them to the launch site is much more than a mere truck down the street. Various special transportation methods are available. All are expensive, and many cost comparisons have been done. However, more cost and time can be saved when possible to manufacture near a launch site.

\section{Method Selection}

Many considerations need to be made when choosing which transporter. Here, we compare cost and schedule factors from a 2005 study, listed in Table 3.

\section{Table 3. 2005 Transporter Comparisons ${ }^{3}$}

\begin{tabular}{|l|c|c|c|c|c|c|c|}
\hline \multicolumn{1}{|c|}{ Criteria } & Road & Rail & Barge & $\begin{array}{c}\text { Air: } \\
\text { C-5 }\end{array}$ & $\begin{array}{c}\text { Air: } \\
\text { AN-124 }\end{array}$ & $\begin{array}{c}\text { Air: } \\
\text { A-300 }\end{array}$ & $\begin{array}{c}\text { Air: } \\
\text { AN-225 }\end{array}$ \\
\hline Trip Days (3000 miles) & 5 & 4 & $11-14$ & 1 & 1 & 1 & 1 \\
\hline Cost Estimate & $\$ 10 \mathrm{~K}$ & $\$ 6-8 \mathrm{~K}$ & $\$ 55 \mathrm{~K}$ & $\$ 110 \mathrm{~K}$ & $\$ 90 \mathrm{~K}$ & $\$ 110 \mathrm{~K}$ & $\$ 115 \mathrm{~K}$ \\
\hline Schedule Risk & Mod & Mod & Mod & Mod db & Mod & High & High* \\
\hline Cost Risk & Low & Mod db & Mod & High & Mod & High & High* \\
\hline *NOTE: Only one AN-225 was in service at the time of this 2005 study. \\
\hline
\end{tabular}

A 2006 USA trade study was done on transporters to carry integrated Constellation vehicles within the KSC launch site, from the VAB to the launch pad. Options considered were:

- New tracked crawler

- Existing Shuttle Crawler-Transporter

- Rail system

- Barge system

- Wheeled vehicle

The recommended best option was to use the existing Shuttle Crawler-Transporter system. It was chosen based on a weighted analysis score, having had lower initial costs, minimal schedule risk, and reasonable maintenance costs. 


\section{Vehicle Transport Examples}

United Launch Alliance (ULA) manufactures both Atlas and Delta vehicles in Alabama. Stages or segments are transported via the Delta Mariner cargo ship to one of two launch sites. The 2000-mile trip to CCAFS typically takes just over a week. However, if they will launch from Vandenberg Air Force Base (VAFB), it takes a month, after going through the Panama Canal and a total of more than 4,000 miles. NASA also used this ship to send the Ares I$\mathrm{X}$ upper stage segments on a 12-day journey from Cleveland to KSC.

Reusable vehicles have a greater concern when using special transport, since they need to turnaround and get back in service quickly. The Orbiters which landed in California would take 2-3 days to fly back to KSC on the carrier aircraft. However, the total impact caused by landing away from the launch site, post-flight activities there, and preparing for aircraft mate and later demate would make the landing-to-processing bay return about 7-9 days longer than a KSC landing.

\section{Location, Location, Location}

You have heard that the three most important factors in choosing a home to buy are location, location, and location. This principle can have significant effects on an overall launch program. In this section on Ground Processing Flow, the separation of various manufacturing, integration, and launch pad locations is a common factor affecting schedule time. Each time flight hardware, GSE, or people have to be transported, cost increases and flow time lengthens. This does not bode well for a desired ORS-type schedule. Customers and suppliers do not always have the luxury of locating every element in an ideal location, but the best scenario would place manufacturing, integration, and launch together. The SLaTS study included a hypothetical illustration which included analysis of what would be ideal locations. Collocation was their recommendation, with a barge taking the integrated vehicle straight from manufacturing on the coast out to a sea launch. Their scenario stated the following benefits, which was more than just flow time:

"Two of the best efficiencies of this plan are the savings in infrastructure and personnel. Because all activities are collocated, we save in equipment, transportation, storage, testing, and others. We'd have to retest parts and systems after intermediate steps, because we eliminate some of the steps to launch. We save in people because we have one location and our specialists move along with the vehicle, from manufacturing, to testing, to launching. We also eliminate travel and relocation costs, because we hire from the local town. An important benefit is the long-term relationships that build over the years of keeping the team together. With these kinds of efficiencies, we pass a great savings to our customers and have fewer risks, which means a higher launch reliability." 3

\section{Ground Processing Support Efficiencies}

Apart from upfront DFO/DFMA and in-flow operations, there are entities established to support operations. These use additional methods and tools for improving cost and schedule. We will look at ILS/IPS and related aspects, since this defines most or all of the support required for an operational system. Then, we will weave-in certain standards and their potential applications to optimize ILS/IPS. Finally, we will briefly mention other support entities.

\section{A. Integrated Logistics Support (ILS) / Integrated Product Support (IPS)}

How do you define "Logistics?" Some think of it as merely a system to manage materials and spare parts. However, there is an entire industry and government community which treats it as a much broader, vital entity, called Integrated Logistics Support (ILS).

ILS is an integrated approach to the management of logistics disciplines in the military, similar to commercial product support or customer service organizations. Although originally developed for military purposes, it is also applied by the private sector as well. In general, ILS plans and directs the identification and development of logistics support and system requirements, with the goal of creating systems that last longer and require less support, thereby reducing costs and increasing ROI. ILS addresses these aspects of supportability from design throughout the lifecycle of the system. DFS is applied in the beginning, and then the operational system supports the design and gives feedback to further improve design. 
DOD acquisition reform of the 1990s produced PBL (Performance-Based Logistics), which enhanced the structure of ILS. Meanwhile, the U.K.'s military created DEFSTAN 00-600, an ILS equivalent to the U.S. model. The next DOD improvement progression in 2009-2011 has further enhanced ILS as IPS (Integrated Product Support), structured as shown in Figure 9.

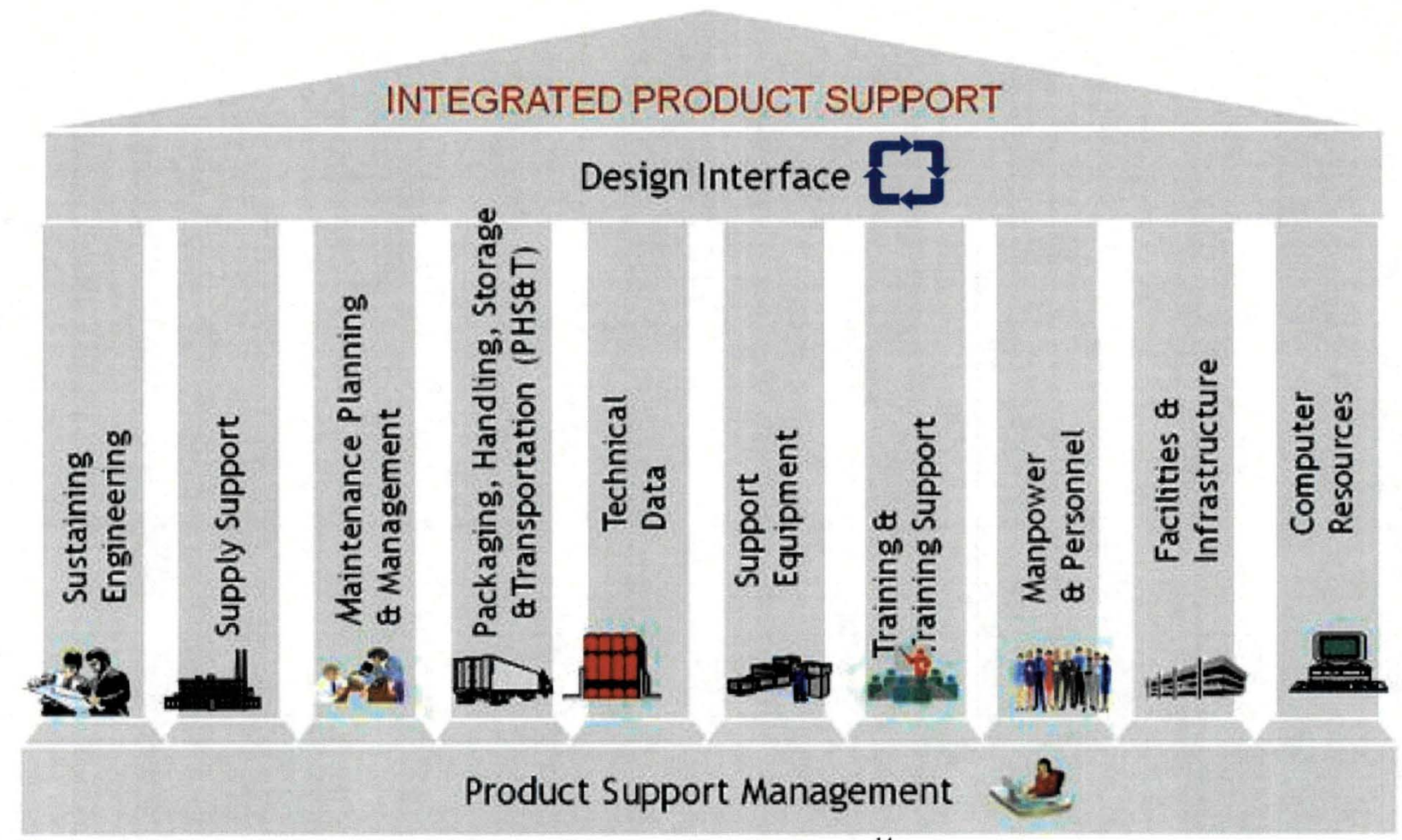

Figure 9. DOD DAU's Integrated Product Support (IPS) Structure. ${ }^{14}$

The traditional 10 elements of ILS are now revised to the following 12 elements of IPS:

\section{Product Support Management (PSM)}

- Objective: Plan and manage cost and performance across the product support value chain, from design through disposal.

- Includes: requirements, contracts, logistics trade studies, budgeting, continuous improvement, etc.

2. Design Interface

- Includes: standardization and interoperability, reliability, availability, maintainability (RAM) design, supportability/sustainability, engineering data analysis, Human Systems Integration (HSI), affordability, nondestructive inspection, corrosion control and prevention, etc.

3. Sustaining Engineering

- Includes: relation to systems engineering, analyses (hazards, failure causes and effects, reliability and maintainability trends, operational usage profiles changes), root cause analysis, technical manual updates, Failure Reporting, Analysis and Corrective Action System (FRACAS), etc.

4. Supply Support

- Includes: Provisioning, bills of material (BOM) management and maintenance, receiving, supply chain assurance, etc.

5. Maintenance Planning \& Management

- Includes: Maintenance concept design, maintenance execution, Level of Repair Analysis (LORA), Failure Modes Effects and Criticality Analysis (FMECA) required repair times determination, Reliability-Centered Maintenance (RCM), etc.

- NOTE: These elements are part of a Logistics Support Analysis/Record (LSA/LSAR).

6. Packaging, Handling, Storage and Transportation

- Self-explanatory. 
7. Technical Data

- Includes: Engineering data maintenance, standards management, technical manuals including Interactive Electronic Technical Manuals (IETMs) management, engineering drawings management, data validation, etc.

\section{Support Equipment}

- Includes: Equipment management, equipment design, maintenance concept integration, Automatic Test Systems, etc.

9. Training \& Training Support

- Includes: On-the-Job Training (OJT), distance learning, acquisition/development/sustainment of Training Aids Devices Simulators and Simulations (TADSS), etc..

\section{Manpower \& Personnel}

- Includes: Identification and acquisition of required numbers of personnel for system operation, system maintenance, system support, and additional personnel identification and justification

\section{Facilities \& Infrastructure}

- Includes: Site activation, and facilities plan management (facilities and facility improvement studies design and execution for every IPS Element, location selection, requirements determination of space, security, equipment, etc.)

\section{Computer Resources}

- Includes: System security/information assurance, manage update the program's Computer Resources Support Management Plan (CRSMP) when major system changes occur, including consideration for: mission critical computer hardware/software operation and support, computer programs and software baselines management, flow/logic diagrams determination, etc. 15

\section{Significance to Space} 2010:

Why is ILS/IPS significant to the space industry? Dr. Kevin Watson of NASA Headquarters Logistics said in

"Neglecting ILS or implementing poor ILS decisions invariably have adverse effects on the life cycle cost of the resultant system...NASA is placing renewed emphasis on the importance of considering the support concept for systems (e.g., a spacecraft) at the earliest stages of a program or project... For NASA space flight projects, the NASA life cycle phases of formulation and implementation are divided into incremental pieces...Of critical importance is the acquisition logistics content (often referred to as supportability planning), which should focus on the tasks that examine all elements of a proposed system or product to determine the logistics support required to keep the system/product/asset usable for its intended purpose and life cycle, and to ensure that the design process results in a system that can be supported at a reasonable cost. With a significant percentage of product life cycle costs occurring in the sustainment phase of the life cycle, applying acquisition logistics in the design phase is the best way to reduce the life cycle costs." 15

Many ground processing activities in the space industry include ILS/IPS elements. We will examine some of these, and standards which apply to them.

\section{B. Standards for Ground Processing}

Standardization is another factor that can improve efficiency and affordability. Industries have seen the pendulum swing from few to too many standards, and the swing back is trying to find an optimal balance of technical, financial, and schedule benefits. The space industry is still young enough that it has seen fewer of these benefits.

\section{Space Industry Standards}

More technical standards for interoperability would simplify designs for assembly, integration, launch operations, mission operations, and turnaround. Various organizations produce such standards and specifications for space, such as:

- American Institute of Aeronautics and Astronautics (AIAA)

- European Cooperation for Space Standardization (ECSS)

- International Organization for Standardization (ISO)

- National Aeronautics and Space Administration (NASA)

- The Consultative Committee for Space Data Standards (CCSDS) 


\section{Other Industry Standards' Potential for Ground Processing}

Global standards for ground processing are also needed. Many sites and contractors operate differently. However, there are aspects that could make each of them more efficient if coordinated standards are agreed upon. Very few standards/specifications exist exclusively for ground processing in the space industry. Part of the reason may be that many methods and tools are the same as other industries. Many standards used in non-space industries have great potential to help ground processing be more efficient. Some are already in use by space companies. However, not everyone knows of or likes all standards which address their processing needs, and not all standards are designed to be complementary when used together. We will recommend a few here which we believe to be key, fitting the keyhole of ILS/IPS.

There is an "S-series" of international specifications, jointly managed by the Aerospace Industries Association of America (AIA) and the AeroSpace and Defence Industries Association of Europe (ASD), as well as one co-managed by the Air Transport Association (ATA). The suite of 'S' standards provides an ILS/IPS package to the advantage of the product lifecycle manager. Harmonization and data exchange mechanisms between the standards supports interoperable communication and concepts of operations utilizing ERP (Enterprise Resource Planning), supply, operations and maintenance planning, and feedback systems for optimizing performance, affordability, and safety.

1. S1000D: International Specification for Technical Publications Utilizing a Common Source Database (CSDB)

- Includes creation and management of Interactive Electronic Technical Manuals/Publications

(IETM/IETP) like maintenance manuals, IPCs, fault isolation manuals, etc.

2. S2000M: International Specification for Materiel Management

- Includes provisioning, spares, etc.

3. S3000L: International Procedure Specification for Logistic Support Analysis (LSA)

- Includes LSAR database and other LSA aspects.

4. S4000M: International Procedural Handbook for Developing Scheduled Maintenance Programs (- will release in 2011)

- Includes scheduled maintenance analyses, RCM, etc.

5. S5000F: International Application Handbook for Operational and Maintenance Data Feedback (- in development, planned release in 2012)

- Includes interfaces with all other S-series specifications and other ILS/IPS elements, passing feedback for optimization.

6. More specifications in the series are in development to further support ILS/ISP functionality.

Two other standards are also working hand-in-hand with the S1000D specification:

7. ASD-STE100: Simplified Technical English, International Specification for the Preparation of Maintenance Documentation in a Controlled Language.

- This document originated from the growing need for clear communication of complex maintenance data. (REF. U)

8. SCORM (Shareable Content Object Reference Model)

- A standard for web-based e-learning. SCORM-compatible training publications can be produced using S1000D. (REF. X)

Our final recommendation is one standard which integrates all of the S-series standards. The S-series are designed not only to work with each other, but under ideal configuration to operate through the Product Life Cycle Support (PLCS) standard, which is Part -239 of ISO 10303, a.k.a. the STEP Standard. PLCS enables the creation and management through time of an assured set of product and support information, which can be used to specify and control required support activities throughout a complex product's life. ${ }^{16}$

\section{Logistics Support Analysis (LSA) / Supportability Analysis (SA)}

Let us look at the LSA standards in more detail. Do you know what an LSA or LSAR are? Many in the space industry do not, yet these are underlying the results of various data that they need or use. Much of ILS has been handled by LSA, managed by an Logistics Support Analysis Record (LSAR) database. LSAR bridges the gap between the Product Data Management (PDM) as-designed/as-built product configurations and the PBL/MRO system. LSAR contains the data needed for the MRO planning and execution processes that will store the asmaintained configuration. 
MIL-STD-1388-1 has been the longtime standard for LSA, and MIL-STD-1388-2 for its LSAR subset. However, these were replaced by MIL-HDBK-502 Acquisition Logistics DOD Handbook, and MIL-PRF-49506 Logistics Management Information (LMI). MIL-PRF-49506 was recently replaced by industry standard GEIA-STD0007 Logistics Product Data, which recovered most features lost since MIL-STD-1388-2B. Meanwhile, S3000L was recently released as an even more optimized international version of an LSA/LSAR specification. During this transition, some have said that Supportability Analysis (SA) replaced the LSA. However, LSAs are still widely used, and many LSAR databases worldwide.

What does an LSA do? SA is the principal tool of ILS. It is the primary means by which the objectives of ILS are achieved and its activities consist of a series of analytical tasks. Supportability requirements are input into an LSA process. The LSA begins by identifying sources of input data and organizing them in a hardware and/or system product structure breakdown, called an LSAR Control Number (LCN). Each item's function is identified and a Failure Mode and Effects Analysis (FMEA) is conducted. A Reliability-Centered Maintenance (RCM) analysis is then conducted of each failure mode, which is used to develop a preventative maintenance (PM) program. A Level of Repair Analysis (LORA) then determines the most cost effective level of repair or discard. Maintenance Task Analysis (MTA) can then be conducted on each item.

All LSA results are documented in an LSA Record (LSAR) database. Commercial-off-the-shelf (COTS) software exists for LSARs, saving cost and development time. This process can result in maintenance procedures, optimal maintenance schedules, and source data generation.

Shuttle had traces of LSA during its design and build, found in scattered documents which make it appear that separate LSA/LSARs were done by various contractors on certain flight and ground hardware. NASA requirements currently list MIL-HDBK-502 and MIL-PRF-49506 as suggested guidelines, so there is no LSA requirement. A partial LSA was built mid-stream for the Orbiter, but never completed or fully utilized, and it eventually was archived during the program. The analyses' results nonetheless were useful inasmuch as was possible, though many did not know how the data was formulated.

The International Space Station (ISS), on the other hand, is still using an LSAR per MIL-STD-1388-2B since many years ago. It is a complex integration example, with synchronized data between international partners from the U.S., Canada, Europe, and Japan (only lacking Russia).

Constellation had an ILS Plan. Requirements specified the use of LSA, for which various vehicle and facility elements (contractors) to form during DDT\&E, until cancellation.

\section{Technical Data}

The ILS/IPS element "Technical Data" is one of the most opportune areas for standardization efficiency. It can include anything from engineering data maintenance to data storage and backup to technical publications (IETMs) used for maintenance, training, or product operation. Here we will focus on the creation, management, access, and exchange of technical data needed to support the product during our definition of ground processing. The same discussion can also apply to use during mission operations.

According to "The Hidden Costs of Information Work," a 2006 IDC study of information/knowledge workers, it revealed that ${ }^{17}$ :

- They spend 48 percent of time searching $(9.5 \mathrm{hrs} / \mathrm{wk}) \&$ analyzing $(9.6 \mathrm{hrs} / \mathrm{wk})$ information.

- They waste $3.5 \mathrm{hrs} / \mathrm{wk}$ in unproductive searches (info not found).

- They waste $3 \mathrm{hrs} / \mathrm{wk}$ recreating content that already exists.

- Not finding the information needed costs an organization employing 1,000 knowledge workers about US\$5.3 million per year.

\section{Design Data and Its Use}

Design data in a design PDM/PLM system may be efficient within itself, but its perspective efficiency is greatly weakened if it is not connected with any other Information Technology (IT) component of an operational system. Considerable time is wasted if manufacturers, operators, and sustainers either cannot locate or access design data or if they only have paper or PDF files.

Model-Based Enterprise (MBE) is the modern trend, designing data systems to allow other systems direct access to 3D models, Bills of Materials (BOMs), and related data. Much of the design data can be reused for technical publications, provisioning, LSA, etc., saving precious hours of research and creation time. 


\section{Technical Publications}

Technical publications, a.k.a. "tech pubs" or technical manuals, are documents containing reference material or instructions for installation, operation, use, maintenance, support, and training requirements for an equipment, machine, process, or system. The modern trend is moving from paper to electronic, which enables numerous time and cost benefits. Atlas and Delta used to use paper-based tech pubs. Now Atlas is all electronic, and Delta is migrating now to the same electronic system.

There are many facets to designing a tech pubs system. The configuration, rules, tools, and methods you choose can greatly optimize or burden the system's time and cost. Here are some Shuttle and Constellation tech pubs improvements history lessons:

1. Make smaller work package chunks.

- Break-up many large books. Status: Partially complete, \& stopped.

2. Renumber all work procedures with one, comprehensive, intelligent scheme

- Reorganize various types by customized NASA-based system-subsystems. Status: Stopped.

- Reorganize various types by Air Transport Association (ATA) -based system-subsystems, as the Shuttle Maintenance Manual (SMM) project. Status: Ran a pilot, incomplete, now reference-only usage.

3. Standardize format and using structured authoring and enable interoperable system interfaces.

- Converted legacy to author in SGML, including interface integration tags for other processing systems. Status: Complete for FRACAS, test, and modification procedures. Partially complete then stopped for routine maintenance procedures.

- Converted again, replacing with custom-tagged Word files, including interface integration tags for other processing systems. Status: Complete for all ground operations and SRB depot.

- Proposed conversion to ATA structure via the SMM project. Status: Ran a pilot, incomplete, now reference-only usage.

- Converted again to integrated, paperless software systems-different systems for ground operations on flight hardware, for ground facilities and equipment, and for each depot. Status: Partially complete during Shuttle operations, now only converting minimum for Shuttle retirement. Same systems were used for Constellation Ares I-X and continue for future space programs. SRB depot's 1st paperless system evaluated electronic step verifications, but it was deemed too costly and thus printing and hand stamping were used. Then a new Ares I paperless system was tested, similar to operations.

- NOTE: ISS converted from an Manual Procedure Viewer (MPV) used for PDF/paper manuals for astronauts to the XML-structured International Procedure Viewer (IPV). Custom format and viewer are used by all international partner countries. Paper is only used for certain critical onorbit procedures/backups. Status: Current.

4. Add graphics and reduce text to provide necessary level of detail for a skill-based workforce.

- Attempted, and some graphics were added, and some detail was reduced. Status: This would have worked for higher skilled workers, but the overriding trend returned to high detail text, to be usable for lowest skill-level worker.

Each of these Shuttle and Constellation efforts was intended to save time and money, and to expand interoperable functionality. Unfortunately, not each effort made it, and what gains were made took various iterations and customizations. However, each of the four goals listed above are built-in to the S1000D standard.

The S1000D international specification for technical publications is our recommended platform. It was designed for air, land, and sea vehicles, as well as support equipment, but it could easily be adapted to space vehicles and sites, too. Since it is a standard, COTS software exists for it. The standard has additional features, including provision for local business rules incorporation, reducing the need for expensive, non-standard customizations.

\section{E. Integrated Business Systems}

Efficient business systems must be established for comprehensive program management. Drawings, specifications, and manuals for an entire launch vehicle are often in different formats from multiple vendors, and they may have proprietary constraints. Nonetheless, the integration team must ensure that all data needed is compatible and visible to each appropriate team member. Ground processing systems for scheduling, tracking, problem resolution, etc. must be well laid-out. 


\section{Integrated Systems Analysis for Army}

See this 2006 analysis of Army systems using standards for lifecycle management:

1. Army has many PDM and logistics systems storing technical data. No one system has an entire product's data, due to multiple contractors.

2. Many enterprise interface solutions are available, but have disadvantages:

- Proprietary 1-to-1 maps are difficult to manage/maintain

- Version-dependent systems require complex upgrade integrations

- Expensive to develop and maintain

3. By using standards, the number of interfaces is greatly reduced because each system will only require an import and export translator from the internal data format of the commercial system to the standard data model.
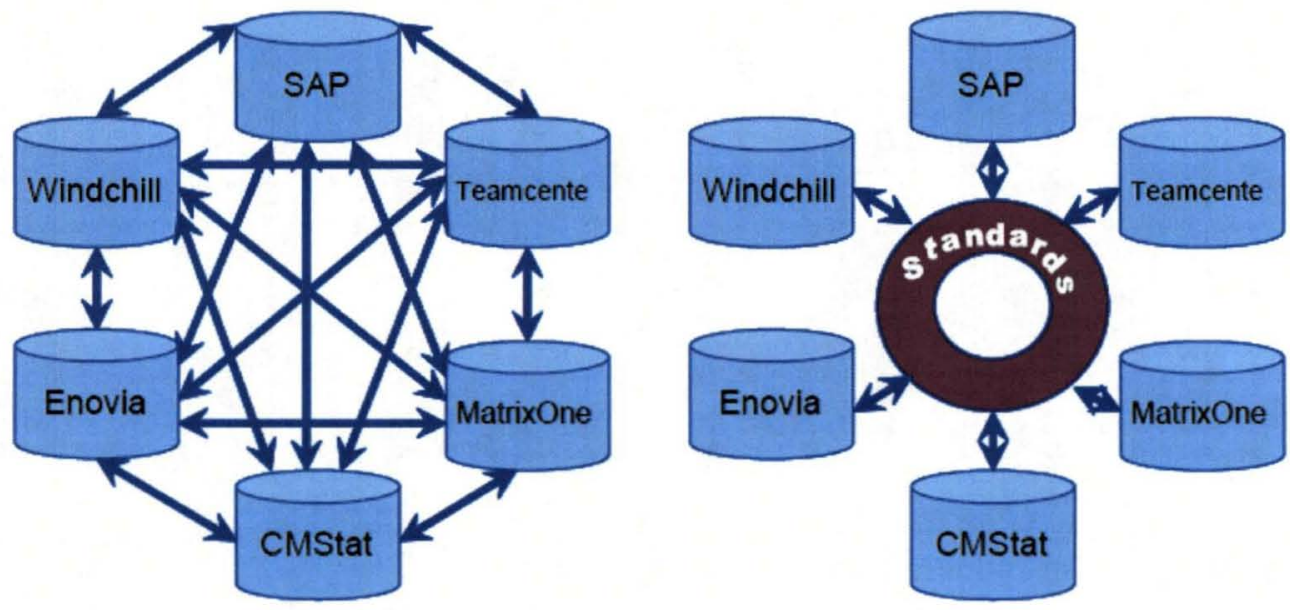

Figure 10. Affect of standards on sample Army business processes. ${ }^{18}$

Now, having chosen standards and found COTS software, optimal efficiencies are available with the right IT integration plan to enable interoperability between tech pubs, LSAR, provisioning, design PDM, etc. When using the entire S-series suite of standards mentioned previously, designed to integrate around the PLCS standard, Figure 11 shows what it could look like. Every element exchanges data fluently, and upgrades to any element are seamless. Upstream and downstream elements are utilizing each other's data - reusing, or repurposing - avoiding the cost and time which would have been spent seeking or recreating needed data. 


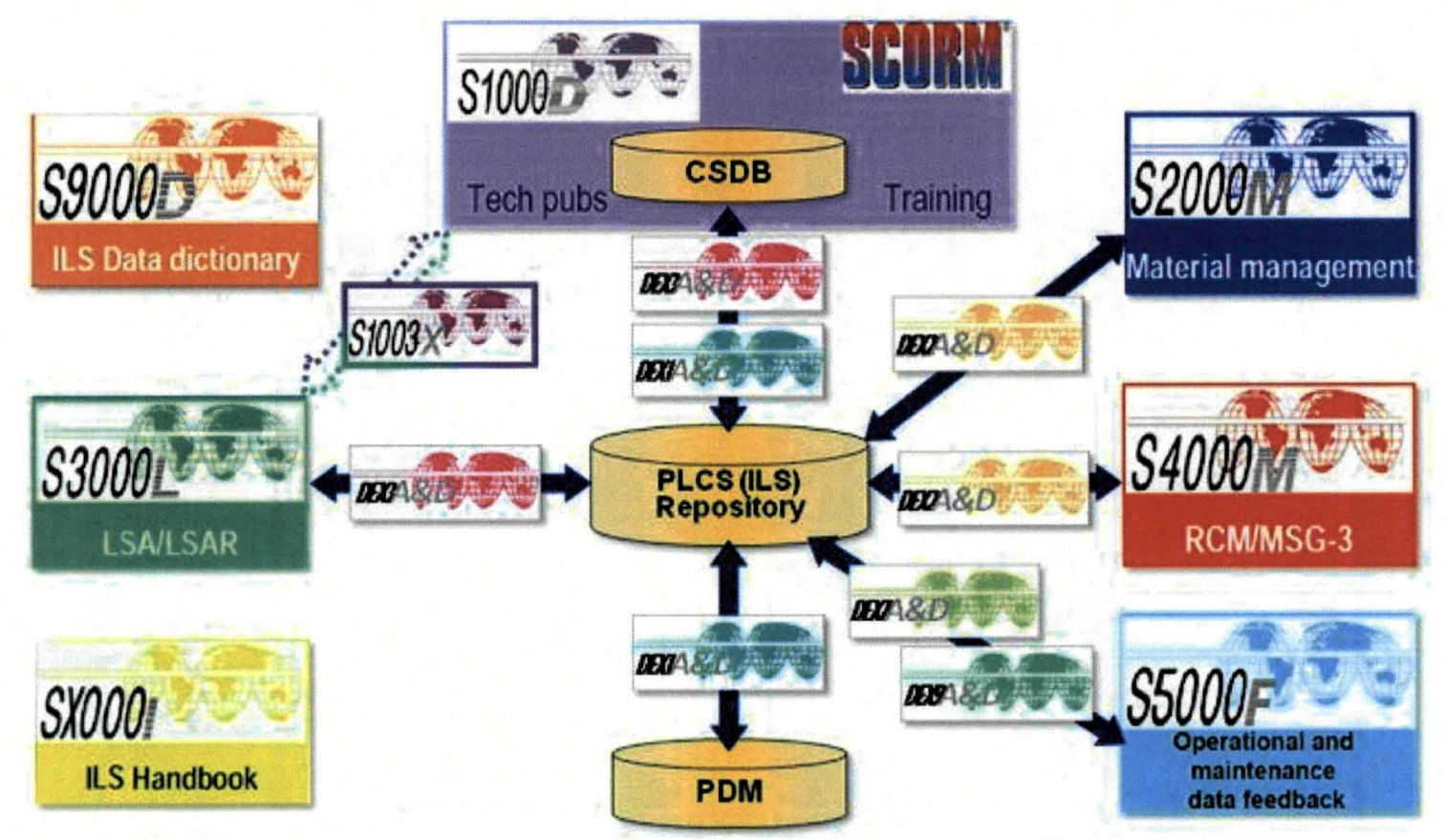

Figure 11. Interoperable ILS/IPS Example System Based on Standards. ${ }^{19}$

Integrated Example Used on Ares I-X, Shuttle, and Next Generation Space Programs

The Ares I-X rocket's entire product structure was a mixture of multiple manufacturers and NASA customer centers, and each major rocket element had its own internal integration. Each element had different drawings, specifications, and numbering schemes. One of USA's jobs was to integrate the integrators.

All was integrated using a collection of COTS toolsets spanning the Requirements Management, PDM, ERP, MRO, MES, and Quality Control arenas. USA's Attentus ${ }^{\mathrm{TM}}$ Integrated Data Management system, in conjunction with a data management portal constructed for Ares I-X ground processing, provided users with a web-based visual interface that integrated multiple application-based datasets into a single logical view of processing operations. This single logical view, linked requirements, drawings, graphics, and other related documents, data, and content to the paperless MES. This allowed one to easily view and drill down into the as-planned versus as-built status of the rocket, on-going processing operations, and non-conformance situations, among other topics. Portal-based dashboards constructed for Configuration Verification and Accounting, Certification of Flight Test Readiness, and Integrated Constraints Management automated real-time insight into these key process management areas. These portal-based dashboards replaced the labor intensive processes traditionally used to assemble this type of data. This saved countless hours for Configuration Management alone, and allowed near real-time verification of the configuration to support milestone reviews and approve readiness. The COTS toolsets were all integrated using two software standards:

- Open Application Group Integration Specification (OAGIS): A common horizontal message architecture that provides XML-based schemas for the Business Object Documents (BODs) flowing within Enterprise Application integrations.

- OASIS Web Services Business Process Execution Language (WSBPEL): A business process orchestration language enabling users to describe business process activities as Web services and define how they are connected to accomplish specific tasks.

These standards linked requirements management, production control, and configuration management across systems, enabling data handoffs from design to manufacturing to assembly to operations. This IT system architecture neared a PLCS approach and was a successful test for future programs' needs. Now, it is being used for Shuttle's Transition and Retirement program, as well as for USA's support for the next generation crew vehicles. This is a good example of efficiency and performance based on the culmination of years of experience, industry standards, and COTS tools. 


\section{F. Other Factors}

Many more factors affect affordability, for which there is not sufficient time to discuss in this paper. Following is a brief list of a few more topics that may be suitable for an expanded future discussion, as well as other topics not listed:

Support Depots: Plan depots for best supportability throughout the lifecycle. Due to DMSMS over the extending lifecycle, Shuttle later replaced fading vendor depots with ones at or near the launch site, enabling better integration and inexpensive local transport. All were merged into the prime contractor at the birth of USA, a joint venture between Lockheed-Martin and Boeing. USA actually assumed some depot and OEM manufacturer responsibilities, though the main contract was processing operations. Constellation, however, predicted it better to send major elements with issues back to remote supplier sites for resolution, and instead utilize the next production element for replacement.

Facilities: Enable the industry's desire for access to shared launch sites, to take advantage of existing infrastructures. Maximize capacity use. Locate offices away from processing facilities with hazardous operations.

Manpower: Schedule hazardous operations only on weekends and off-shifts to avoid unproductive time. Crosstrain personnel in various disciplines to be versatile and productive, rather than "hurry up and wait."

Training: Plan a balance of baseline industry certification, company-owned enterprise learning system for OJT, contract-specific (delta) skills training, and facility-specific access / safety / regulatory training through institutional providers. Certify workers during work tasks when possible, saving training time.

Quality: Monitor the project management principle which describes "too much" quality, as it can add unnecessary cost. Consider designing higher quality into the hardware, which requires less ground inspection and test.

Metrics: Establish sufficient metrics to measure your true time and cost, and any improvements.

\section{Conclusion}

There are many ways in which the space industry can learn from other industries - even airplanes. Cost may not be easy to reduce in technical design due to the unique requirements of space, but some design could be changed to better fit ground operations - for flight hardware, support equipment, and facilities. We can adopt more efficient methods and tools used in other industries for manufacturing and operations. We can learn from existing and past space vehicles, whether developing a new space vehicle, payload, or facility, or looking for ways to reduce costs with existing ones. If we apply DFMA/DFO/DFS, ground flow operations best practices, ground support systems using ILS/IPS systems, industry ground standards, coupled with the customer choosing location, location, and location, then ground processing will prove itself as a key to affordability.

Here is one more twist to think about. Astronauts in orbit, whether in a spacecraft or a space station, also do some of the same or similar activities which are done on the ground. They perform operations, testing, and maintenance, and they have to manage their logistics of parts, materials, equipment, and other supplies. Yes, they have special conditions, but why not look at efficiencies to be gained from including them in the same ground processing methods and tools? We are already looking at that, too!

We said just one more twist, but please look at one more. When we get to the Moon, an asteroid, or Mars, consider yet another potential application of the term "ground!"

\section{Acknowledgments}

Many people contributed to this research. The authors thank:

- United Space Alliance, LLC (USA):

$\circ \quad$ Wayne Bingham, Orbiter Flow Manager

- Rick Bolton (retired), Logistics Support Analysis Specialist

○ Dan Ciccateri, Deputy Director, Launch \& Recovery Services Engineering

- Mike Chappell, Orbiter Flow Manager

○ John Cipolletti, Director, Launch \& Recovery Services Engineering

- Jackie Farley, Manager, ISS Logistics \& Maintenance

- Pat Floyd, Senior Engineer, Mechanical Systems 
- Mike Hurt, SODF Manager

- Steve Kane, Quality Assurance, SQ\&MA, Launch \& Recovery Services

o Peter Kent, Manager, Content and Asset Management Systems \& Technology

- Mike Leppert, Staff, Solid Rocket Booster and Marine Operations

o Frank Norris, Lean Six Sigma Black Belt, Launch \& Recovery Systems Engineering

- Tony Quandt, Manager, ISS Maintenance Systems

- Angel Telles, Ground Logistics Support

o Katrine Stelges, Industrial and Human Engineering

- Edie Stull, Project Support

- Alliant Techsystems, Inc. (ATK): Ted Shaffner, Deputy Director, Florida Operations

- NASA: Rex Englehardt, Mission Manager with NASA Launch Services Program

- Orbital Sciences Corporation: Chris Demars, Director of Florida Operations

- S1000D Organization: Jan Haslam, Secretary of the S1000D Steering Committee

- Space Exploration Technologies Corp (SpaceX): Scott Henderson, Director of Mission Assurance \& Integration

- United Launch Alliance (ULA): Joshua Weilnau, Systems Engineer, Atlas Launch Operations

\section{References}

1 “Unconventional Spacelift”, SPACECAST 2020 Symposium, Air University, Maxwell Air Force Base, AL, June 1994, p. 15-16. URL: http://csat.au.af.mil/2020/.

2 Finger, G.W., Moore, S.W., and Gulliver, B.S., "Implementing Operationally Responsive Launch Sites", Reynolds, Smith \& Hills, Inc., AIAA SpaceOps 2010, Huntsville, AL, pp. 1, 7.

3 Larson, Kirkpatrick, Ryan, and Weyers, Space Launch and Transportation Systems, Space Technology Series, 2005, a cooperative activity of the U.S. DoD and NASA, unpublished-available through NASA Libraries or Defense Information Technology Service, Vol. I, pp. 63, 330-333, 340, 365-370, 346, 305, 346, 349-358, 346-348, 63, 335, 67, $291,345$.

4 Zapata, E., et al, "A Guide for the Design of Highly Reusable Space Transportation", Space Propulsion Synergy Team, Aug. 29, 1997, (unpublished), p. 33-34. URL: http://science.ksc.nasa.gov/shuttle/nexgen/rlv guide.htm [cited Sep. 6, 2011].

5 Mason, H., "Product Life Cycle Support (PLCS) The Information Backbone to transform the Logistics Enterprise", BAE Systems, presentation at Transatlantic PLCS/10303 meeting, for U.S. DoD UID Program Office, Feb. 16, 2006. URL: http://www.acq.osd.mil/dpap/pdi/uid/iso 10303 step_ap_239 plcs.html .

6 McCleskey, C.M., Claybaugh II, W.R., "Independent Space Operators: Gaining a Voice in Design for Operability", NASA, presentation at AIAA SpaceOps 2006 Conference. URL: www.aiaa.org/spaceops2006/presentations/55867.ppt .

7 Watts, S., "Design for Manufacturing and Assembly", Redstone Arsenal, AL, Apr. 28, 2005, 40th Annual Armament Systems: Guns - Ammunition - Rockets - Missiles Conference \& Exhibition. URL: http://www.dtic.mil/ndia/2005garm/thursday/watts.pdf.

8 "Designing and Assessing Supportability in DOD Weapons Systems: A Guide to Increased Reliability and Reduced Logistics Footprint”, Oct. 24, 2003, Office of Secretary Defense, p. 9. URL: http://www.acq.osd.mil/dte/docs/FINAL-GUIDEwith-Memo-October24-1.pdf.

${ }^{9}$ Fowler, "The Future of Product Support", Defense AT\&L, Mar-Apr 2010, p. 5. URL: https://acc.dau.mil/CommunityBrowser.aspx?id=372214 .

${ }^{10}$ Vozoff, M., Couluris, J., "SpaceX Products - Advancing the Use of Space", Space Exploration Technologies (SpaceX), AIAA SPACE 2008 Conference \& Exposition, San Diego, CA, p. 6.

${ }_{11}$ Input data supplied by ATK (Alliant Techsystems, Inc.).

12 Norris, G., "Air Force Study Points To Reusable Orbiter", AviationWeek.com [online magazine], Sep. 20, 2010. URL: http://www.aviationweek.com/aw/generic/story channel.jsp?channel=defense\&id=news/awst/2010/09/20/AW 09 20 2010 p76 $\underline{-253108 . x m l}$ [cited Sep. 6, 2011].

${ }^{13}$ Panontin, T.L, "Lessons from the Shuttle Independent Assessment", NASA Ames Research Center, RMC III, September 19, 2002, p. 7. URL: http://klabs.org/DEI/lessons learned/arc lessons/rmc siat.pdf.

14 "Product Support Manager Guidebook", U.S. DoD, Apr 2011, Appx A, pp. 81-93. URL: http://www.acq.osd.mil/log/mr/library/PSM_Guidebook_April2011.pdf.

15 Watson, K., Carpenter, D.E., "Systems Engineering and the Role of Integrated Logistics Support (ILS) within the NASA Project Life Cycle Framework”, NASA, AIAA SPACE 2010 Conference \& Exposition, Anaheim, CA, pp. 1-3.

${ }^{16}$ Product Life Cycle Support (PLCS) Resources, website sponsored by Eurostep for ISO standard 10303-239. URL: http://www.plcs-resources.org/ [cited Sep. 6, 2011].

17 "The Hidden Costs of Information Work", a 2006 IDC (International Data Corporation)study of information/knowledge workers in financial services, government, manufacturing and healthcare organizations in the U.S. is quoted in numerous articles, including those listed here and used for this paper. URLs: Used citations at http://h41320.www4.hp.com/ipge/pdf/Spotlight_on_costs 3.pdf , http://msdn.microsoft.com/en-us/library/bb887531.aspx , 
http://www.tribridge.com/Libraries/White_Papers/WP-EnterpriseSearchMicrosoft.sflb.ashx http://www.opentext.com/2/global/press-release-details.html?id=2203 [cited Sep. 6, 2011].

${ }^{18}$ Rachuri, S., Foufou, S., Kemmerer, S., "Analysis of Standards for Lifecycle Management of Systems for US Army --- a preliminary investigation”, Aug 2006, NIST (National Institute of Standards and Technology) Report NISTIR 7339, p. 6. URL: http://pdesinc.aticorp.org/downloadable files/NIST-Report_StdsLefeCycle-publish.pdf .

${ }^{19}$ Ingalls, J., "S1000D and Beyond for Space", May 2011, United Space Alliance, presentation at Spring 2011 Aerospace Industries Association (AIA) / Joint Services Technical Publications Workshop, Clearwater, FL, p. 33. URL: https://acc.dau.mil/CommunityBrowser.aspx?id=452827\&lang=en-US 


\title{
Ground Processing Affordability for Space Vehicles
}

\author{
John Ingalls
}

Sep. 27-29, 2011

AlAA Space 2011 Conference \& Exhibition

* United Space Alliance 


\section{About the-Authors}

- John Ingalls, United Space Alliance, LLC (USA)

- Senior Engineer, Launch \& Recovery Systems

- S1000D, USSMG (U.S. Specification Maintenance Group)

- International Specification for Technical Publications

- AIA's SSFA (Strategic Standardization Forum for Aerospace)

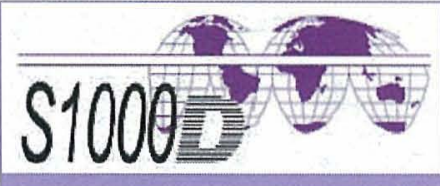

- Russell Scott, United Space Alliance, LLC (USA)

- Deputy Director, Launch \& Recovery Systems

- Lead, Enterprise Lean Six Sigma Master Black Belt

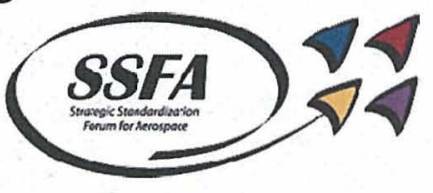

- Member, ASQ and PMI

- About USA

- Joint venture, Boeing and Lockheed-Martin

- Numerous space industry services and products

- John \& Russ are from the Florida division at NASA KSC
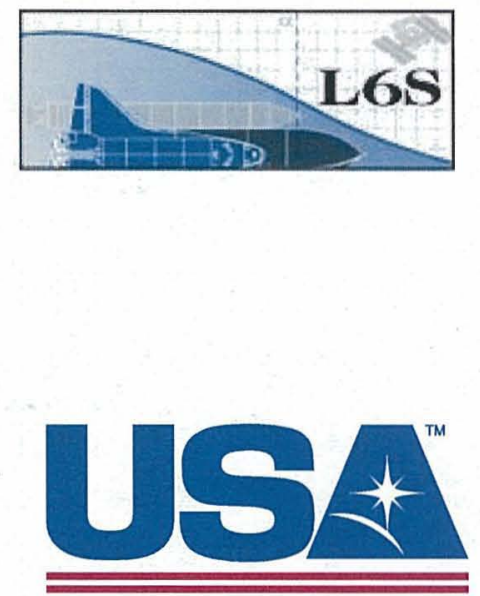

United Space Alliance 


\section{Outline}

- Introduction

- Ground Processing Significance

- Ground Processing by Design

- Ground Processing Flow Efficiencies

- Ground Processing Support Efficiencies

- Conclusion

- Questions 


\section{Introduction}

- Global Space Market Factors

- Economics, commercial space, ORS (Operationally Responsive Space), etc.

- Affordability

- Find ways to decrease costs

- Reduce time, yet, maintain quality and safety

- What efficiencies can be implemented?

- Most space vehicle time is on the ground: flow \& infrastructure cost

- Why is so little ground attention given during design?

- Space vs. Other Industries

- Lessons learned from space industry can help

- Lessons learned from other industries can also help 


\section{Introduction-Analogy:-Plane vS. Space Vehịc:e}

"... if airlift operations were conducted in the same manner as spacelift operations,

1. "each mission would begin with planning to determine payload characteristics well in advance of launch.

2. "The aircraft,...late-1950s vintage, would be selected to optimize performance based upon this payload, wasting as little performance margin as possible.

3. "Once the parts of the aircraft arrived at the airport, they would be wheeled out on the runway, one of the most expensive pieces of infrastructure,

4. “...major components of the aircraft would be assembled

5. "and then the payload would be loaded.

6. "Since each operation is different, ground crews would have to improvise procedures for each takeoff.

7. "....any adverse weather conditions would delay takeoff. ...meantime, no other aircraft could takeoff or land...

8. "Once the aircraft was finally launched and delivered its payload, it would be scrapped.
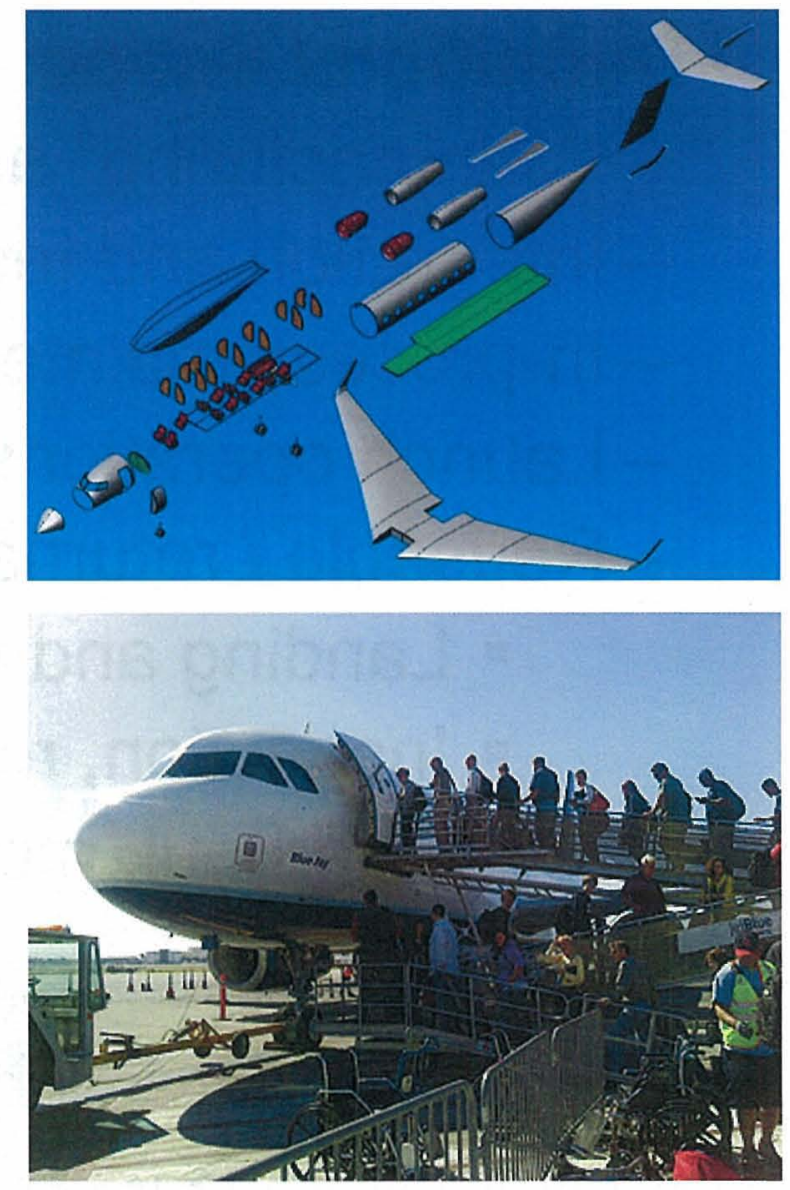

"When juxtaposed in this fashion, it is clear that this approach is severely flawed and in need of major changes." 


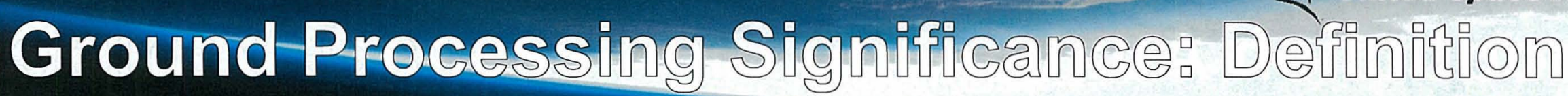

- Focus on Ground Processing, Ripe for Efficiencies

- Definition / Scope:

- "Manufacturing" assembly operations (-not part fabrication)

- Integration and test

- In-process maintenance and repair

- Launch operations

- Reusable / returnable vehicles also include post-flight activities:

- Landing and recovery

- Inspection, refurbishment, maintenance

- Overhaul, modification, reconfiguration

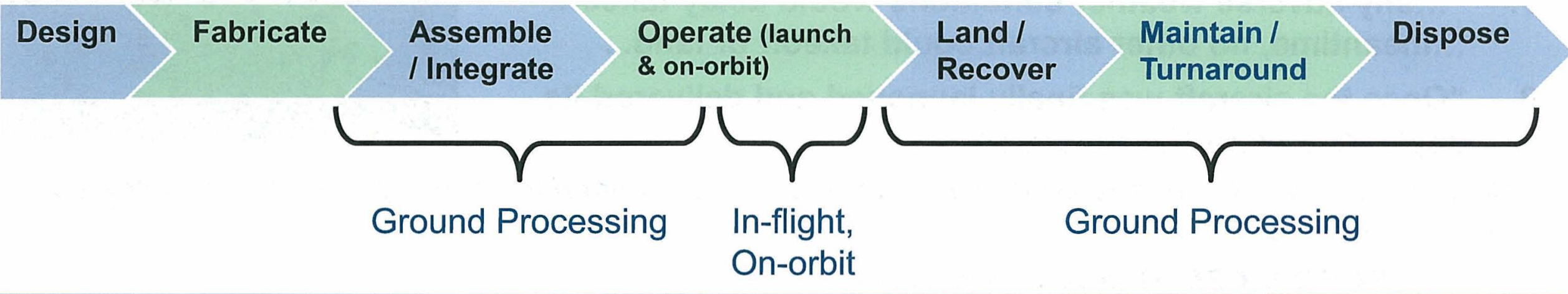




\section{Ground-Processing-SigmifficanGe: COSt?}

- True Cost Comparisons Are Difficult

- Variable funding, requirements/motives, shared infrastructures

- Knowable Cost Examples

- Shuttle - most expensive, but manned

- Pegasus \& Taurus - efficient operations, but high component cost

- Ariane \& Delta - reliability attracts traffic, because it lowers costs

- RLVs vs. ELVs

- RLVs can cost less over lifecycle, but only after sufficient flight rate

- General Principle

Half of "ground processing" cost is infrastructure

$\sim$ Half of cost is for principle processing functions 


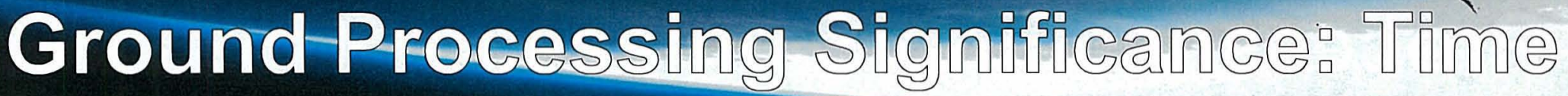

- Time Is Money: Major Affect on Cost

- Time As a Major Objective: ORS goals Develop, Deploy, Employ

- Manned RLV vs. Other Vehicle Flows: All are ripe for efficiencies

- Example Turnaround - Shuttle, 135-165 Days Landing to Launch

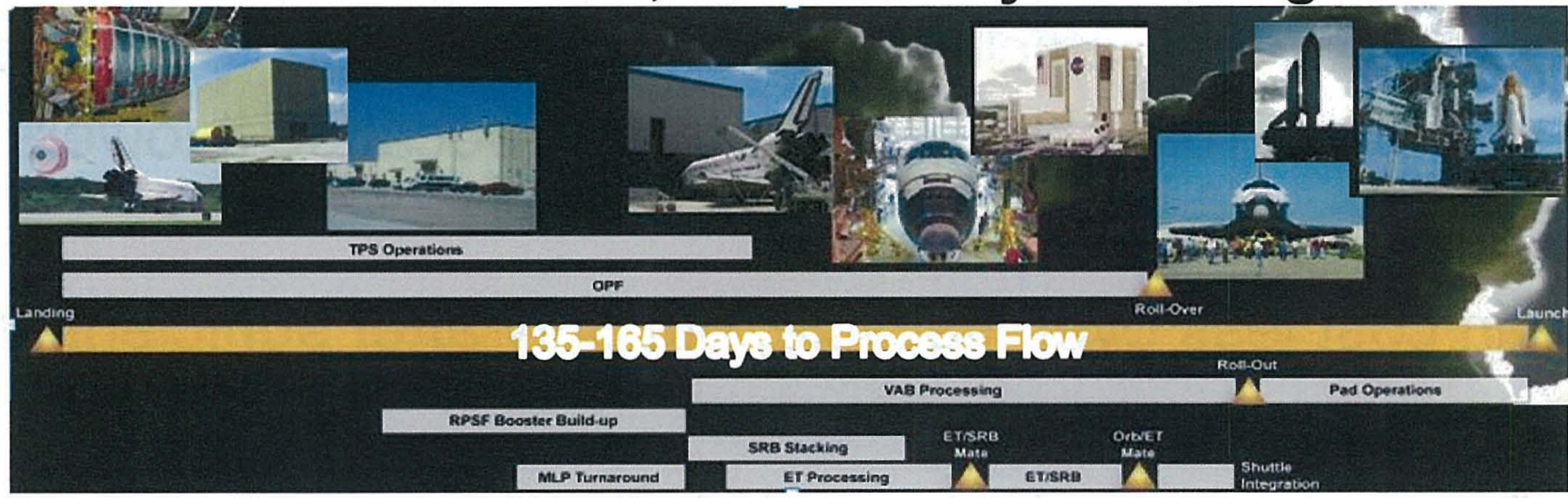

- Example Turnaround - Future Estimates, Vehicles at KSC (chart)

\begin{tabular}{|c|c|c|c|c|c|}
\hline \multirow[b]{2}{*}{$\begin{array}{l}{ }^{*} \mathrm{CBC}=\text { Common Booster Core) } \\
{ }^{*} \text { Depends on configuration options and serial or } \\
\text { parallel support }\end{array}$} & \multicolumn{5}{|c|}{ Estimated Days for Example Vehicle Configurations if Launched at KSC } \\
\hline & $\begin{array}{c}3 \mathrm{CBCs}^{*} \text {, } \\
\text { 2nd Stage, } \\
\text { Cryo fuel }\end{array}$ & $\begin{array}{l}3 \mathrm{CBCs}^{*} \text {, } \\
\text { 2nd Stage, } \\
\text { RP-1 fuel }\end{array}$ & $\begin{array}{c}\text { 1st Stage, } \\
\text { 2nd Stage, } \\
4 \text { SRBs }\end{array}$ & $\begin{array}{l}\text { 1st Stage, } \\
\text { 2nd Stage }\end{array}$ & $\begin{array}{c}\text { 5-segment SRB, } \\
\text { Fwd Assy, } \\
\text { 2nd Stage }\end{array}$ \\
\hline Vehicle Assembly(2 shifts,\& some $3^{\text {rd }}$ ) & 20 & 20 & 24 & 16 & 50 \\
\hline Launch Operations (3 shifts) & 3 & 3 & 3 & 3 & 8 \\
\hline Facility Turnaround (Pad, MLP, VAB) ${ }^{* *}$ & $20-40$ & $10-30$ & 12-27 & $10-25$ & $30-60$ \\
\hline Minimum Time Between Launches** & 24-38 & 14-38 & 9-44 & $9-34$ & N/A-to-78 \\
\hline
\end{tabular}




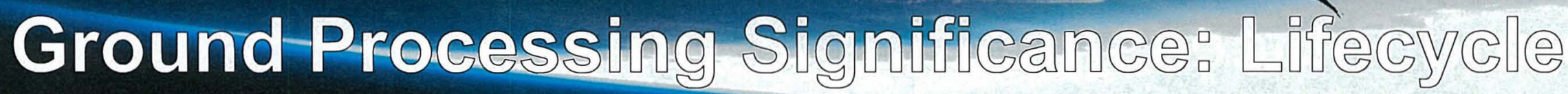

- Lifecycle Phase: Operational / In-Service Use

- Much larger timeframe (and cost) than design and manufacturing

- ISO 10303-239 calls it Product LifeCycle Support (PLCS)

- ELVs still apply, due to repeat build and launch

- Therefore, Design for Supportability (DFS)

- Later, support the design, and continue feedback loop

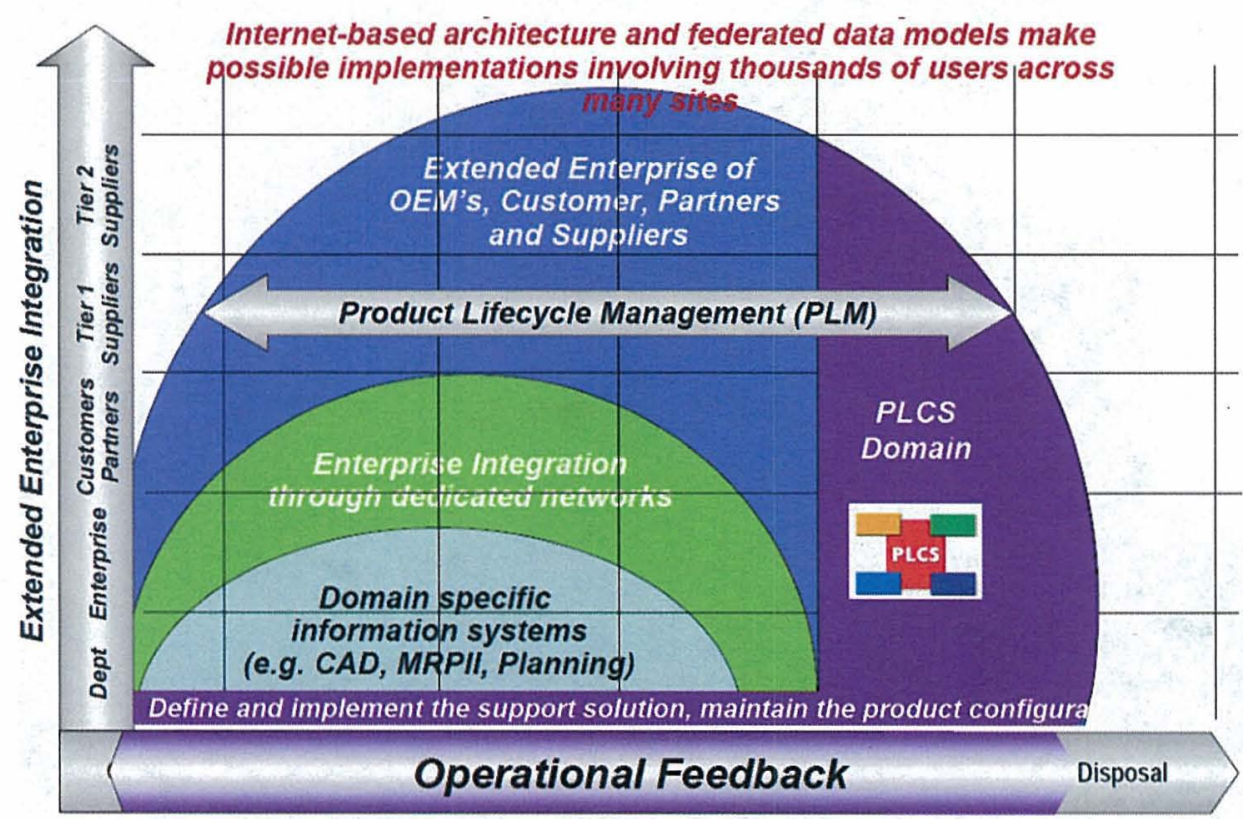

Design View of Lifecycle

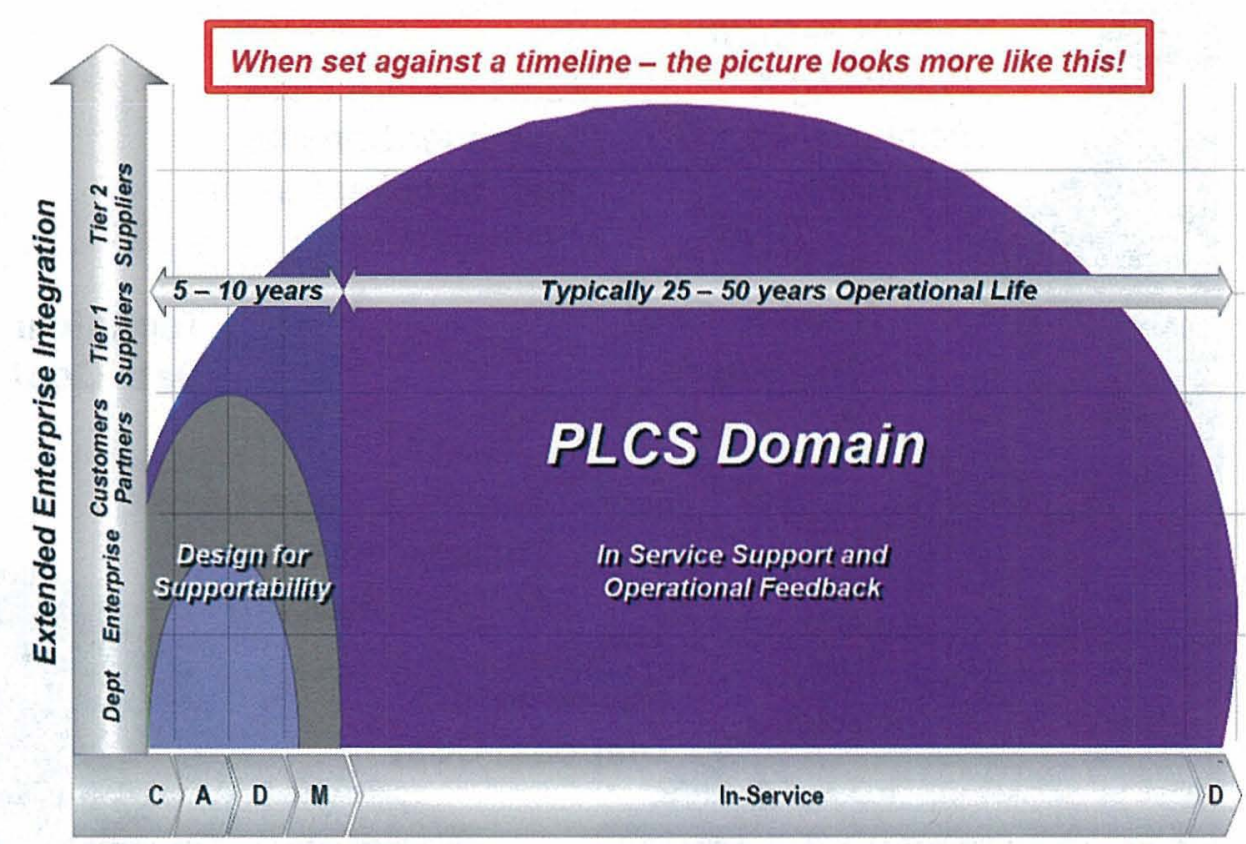

Operational Time View 


\section{Ground-Processing by Desigin}

\section{- Supportability Considers Total System "Cost of Ownership"}

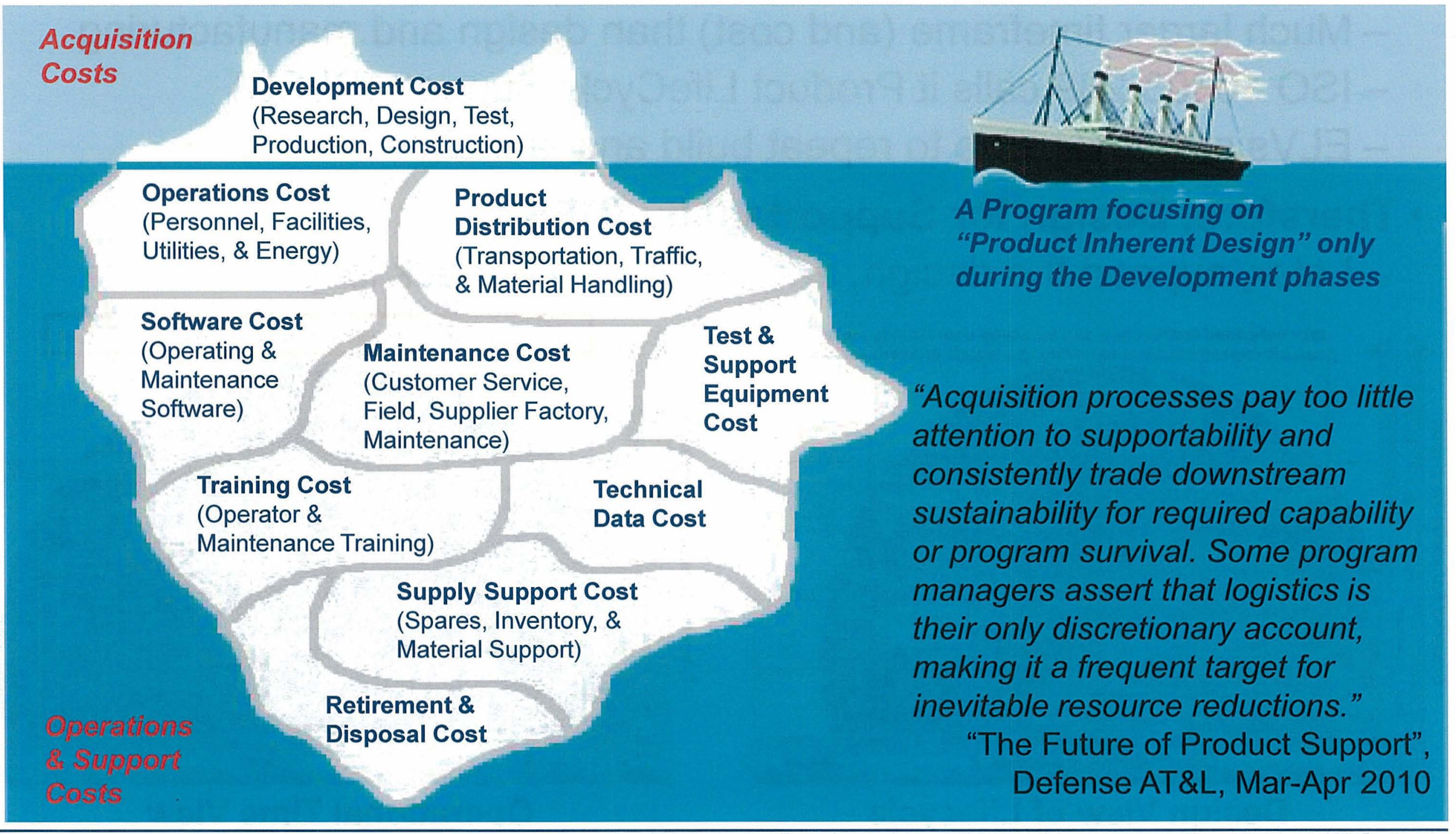

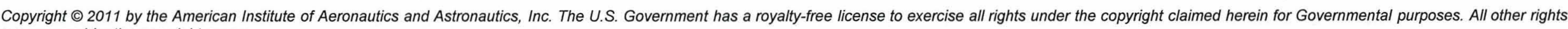
are reserved by the copyright owner. 


\section{Ground Processing by - Desigin}

- The Need to Design with the Ground

- $~ 85 \%$ operating \& support costs set early in program

- Documented in many lessons learned, but often is still not learned

- Three Overlapping Methods

- Design for Manufacturing and Assembly (DFMA)

- E.g.: Ares I-X BDM/BTM mod on $1^{\text {st }}$ stage

- Design for Operations / Operability (DFO)

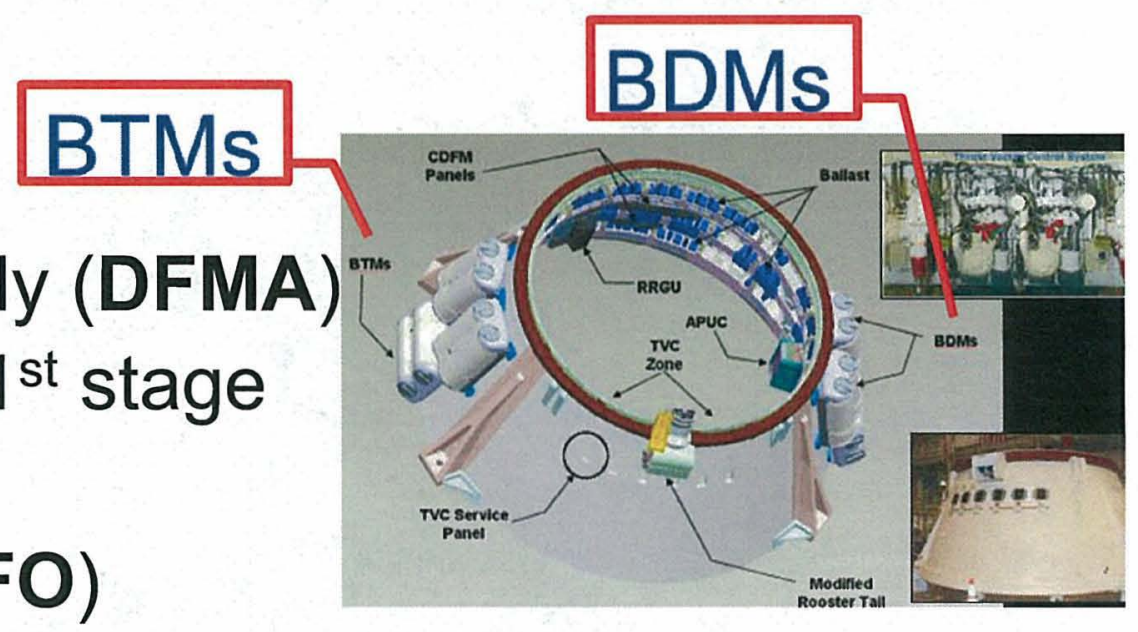

- E.g.: USA's Human Engineering Modeling \& Performance (HEMAP) efforts for future vehicles (-see video:)

- Design for Support / Supportability (DFS)

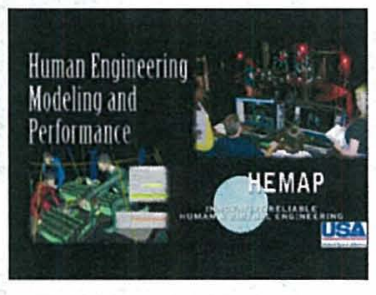

- U.S. \& U.K. militaries mandate DFS via ILS (discussed later)

- E.g.: DC-X Delta Clipper experimentally proved DFO \& DFS 


\section{Ground-Processing by Desig]n}

- Lessons Learned Example: Space Shuttle Processing
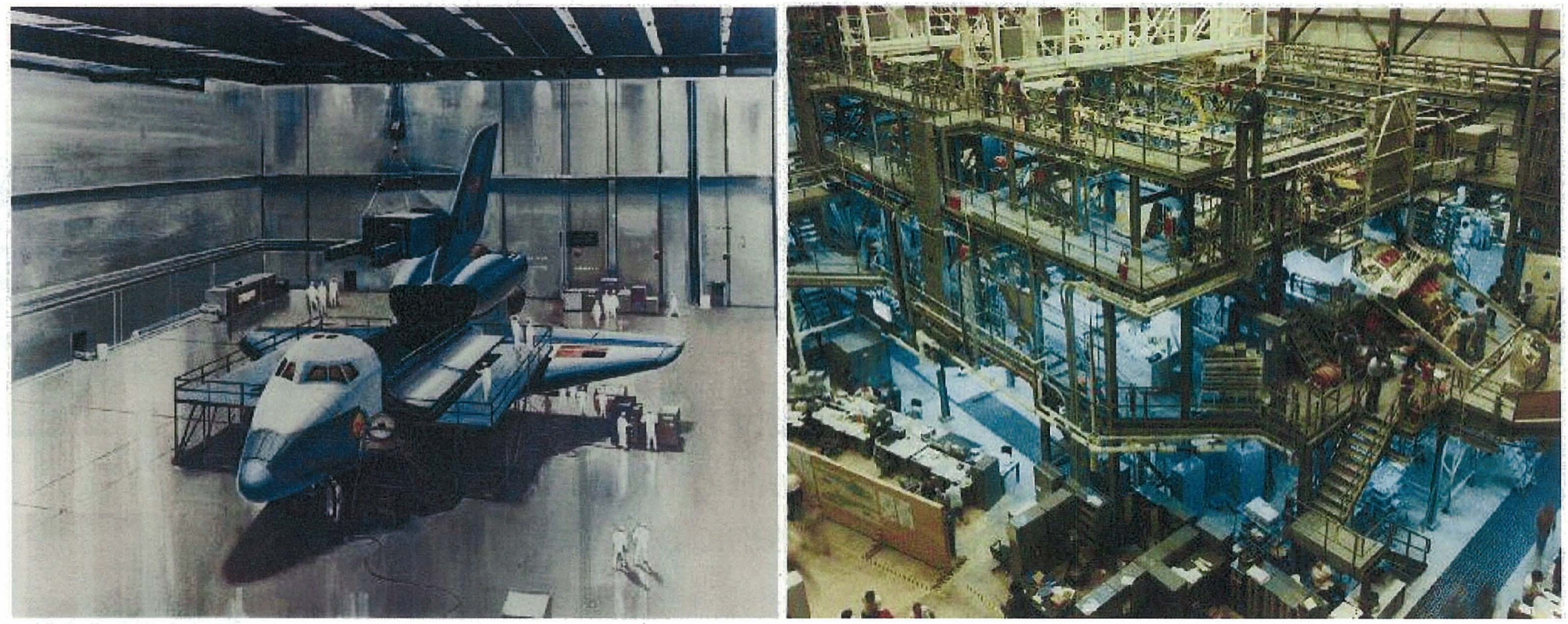

Original Shuttle Turnaround Vision (around 1974)

Actual Shuttle Turnaround Reality, as of 1981 (1 ${ }^{\text {st }}$ Flight) 


\section{Ground-Processing Flow Effileiencies}

- Manufacturing Assembly Operations Considerations

- Assemble before pad vs. assemble at pad

- Horizontal assembly, like Russians, \& manufacture near launch site

- SpaceX has $>90 \%$ internal design through operation

- Helps control cost / schedule / quality

- Integration and Testing (I\&T)

- Minimize impacts during integration and test

- E.g. - Ares I-X savings: RoCS hazardous service offline

- Make standard procedures for rapid issue resolutions

- Avoid unnecessary testing

- Consider on-orbit validation \& use RCM

- Multi-contractor/-element vehicle example challenges:

- USA integration of Space Shuttle

- USA integration of Constellation's Ares I-X 


\section{Ground-Processing Flow ErffielenGies}

\section{- Launch Operations}

- Testing continues through countdown, often producing issues

- Same ground processing methods are needed for rapid resolution:

- DFO should plan for easy access to repair/replace components

- Preapproved acceptable defect limits \& standard procedures
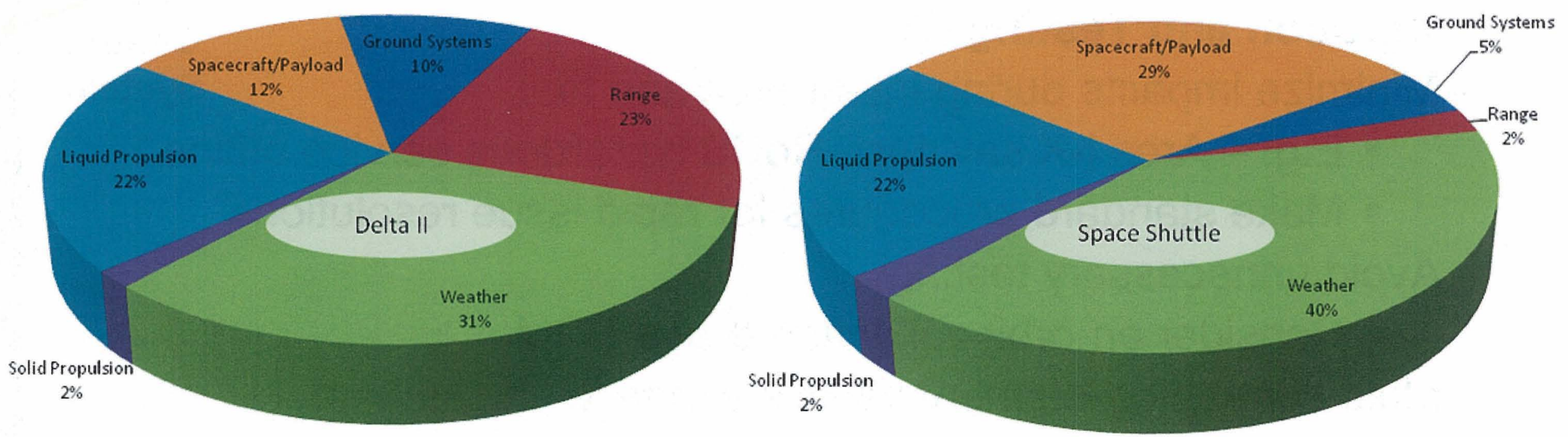

Causes of Countdown Delays - Delta II and Shuttle 


\section{Ground-Processing Flow Effriciencies}

- Post-Flight Operations

- Ground operations begins post-flight for RLVs and "returnables"

- Landing \& Recovery:

- New Reusable Booster Systems (RBS) plan to cut costs $50 \%$

- Ideally, land at turnaround maintenance site

- Evaluate impacts - Orbiter issues after White Sands landing

- Turnaround: Inspection, deservice, payload removal

- Boosters require significant disassembly and refurbishment

- Standardize payload interfaces/procedures for reconfigurations 


\section{Ground-Processing Flow Efficiencies}

- Maintenance, Repair, \& Overhaul (MRO)

- ELVs require some vehicle maintenance/repair

- RLVs require extensive MRO

- Unplanned MRO (Shuttle $\sim 60 \%$ Overall)

- Nonconformances (plan $>30 \%$ margin)

- Shuttle count was high (see figure)

- Much is due to collateral damage

- Component failures

- Make preapproved solutions:

- Allowable defect limits

- Standard rework \& repairs

- Late modifications \& tests

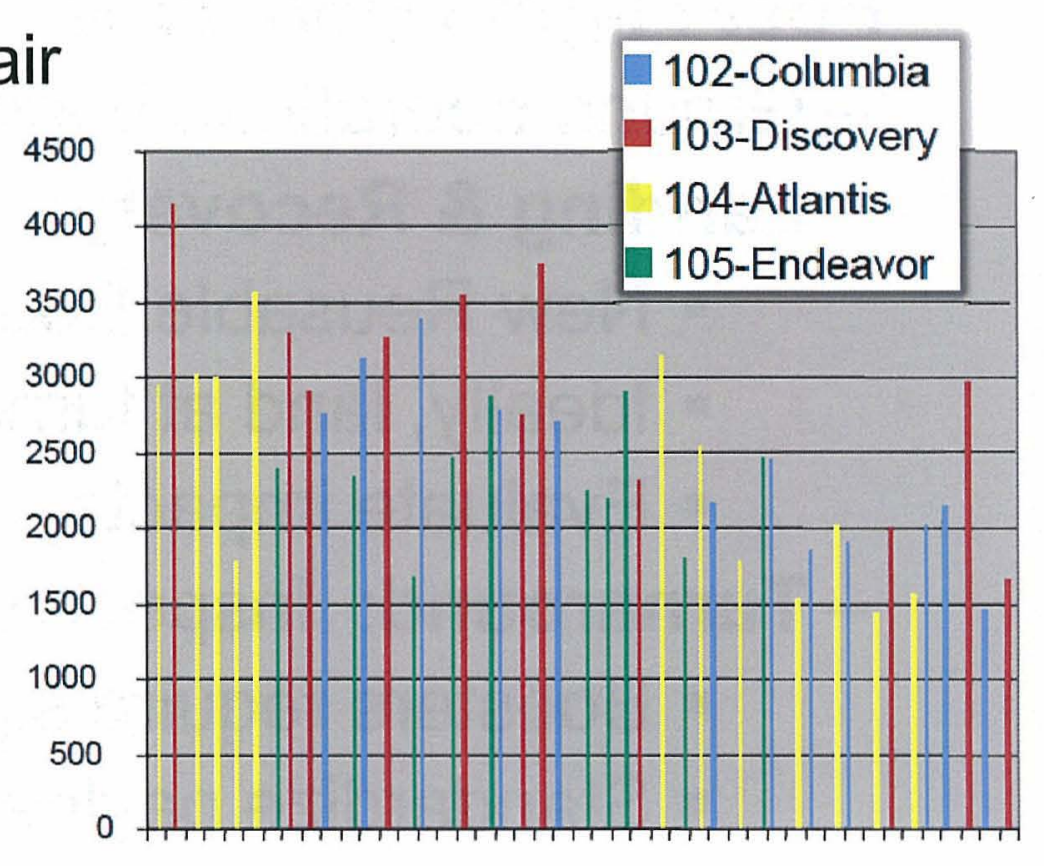

- Planned MRO

- Scheduled maintenance in-flow \& overhaul

- Overhauls

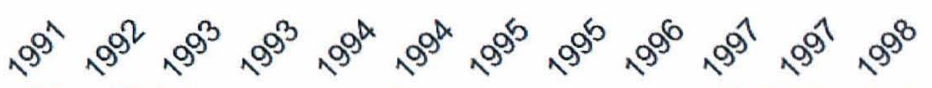
\# of Nonconformances / Flight

- RLV flow maintenance often includes overhaul-type work

- Official Orbiter overhaul was every 8 flights, lasted 1-2 years

- Modifications and technology upgrades

- Shuttle included many during flow-More efficient at overhaul 


\section{Ground-Pro.essing-Swppor Ekficiencies}

- Support: Methods/Tools for In-service / Use Life Cycle Phase

- Of many support aspects, focus is on ILS/IPS here

- Integrated Logistics Support (ILS) / Integrated Product Support (IPS)

- Models: military "logistics", commercial "product/customer" support

- ILS/IPS is a Key Method

- "Neglecting ILS or implementing poor ILS decisions invariably have adverse effects on the life cycle cost of the resultant system...

- "NASA is placing renewed emphasis on the importance of considering the support concept for systems (e.g., a spacecraft) at the earliest stages of a program or project...

- "...applying acquisition logistics in the design phase is the best way to reduce the life cycle costs."

- Dr. Kevin Watson of NASA HQ Logistics 


\section{Ground-Pro.cessing-Support Esflciencies}

\section{- 12 Elements of IPS}

\section{- (Revision of traditional 10 elements of ILS)}

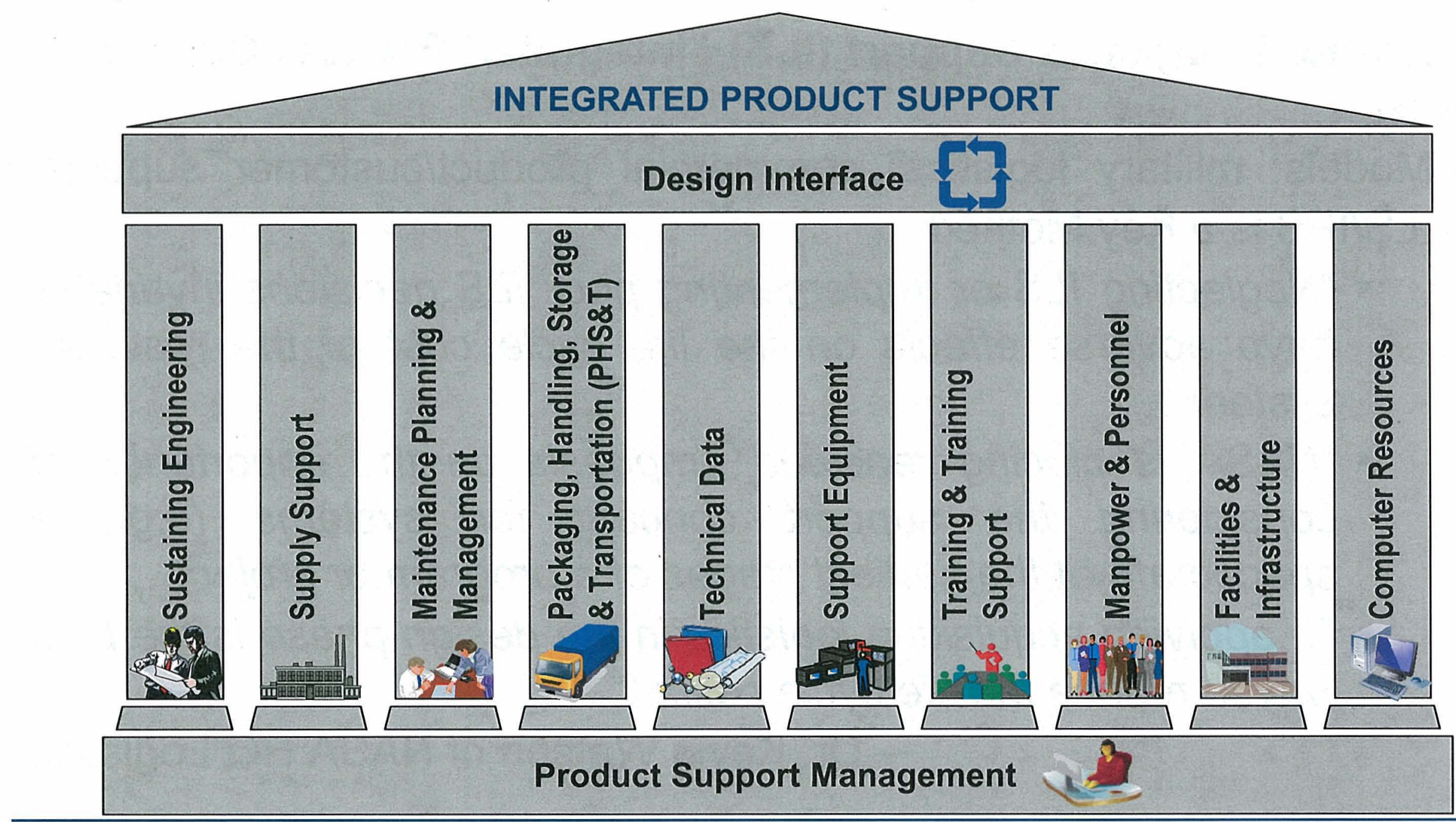




\section{Ground-Processing-Swppor EHfleDencies}

Organization of Technical Information (IPS Elements) is Key According to 2006 study of information/knowledge workers' time spent:

- $48 \%$ - searching ( $9.5 \mathrm{hrs} / \mathrm{wk})$ \& analyzing ( $9.6 \mathrm{hrs} / \mathrm{wk})$ information.

- $3.5 \mathrm{hrs} / \mathrm{wk}$ - in unproductive searches (info not found).

- $3 \mathrm{hrs} / \mathrm{wk}$ - recreating content that already exists.

\section{Recommend an Interoperable Suite of ILS/IPS-based Global Standards}

- Technical Data - Focus Points:

- Design Data: drawings/models, configuration, etc., often in a PDM/PLM

- Technical Publications ("tech pubs"): for maintenance, training, operation

- Training \& Training Support - Focus Points:

- Training publications, can be compatible with Technical Data

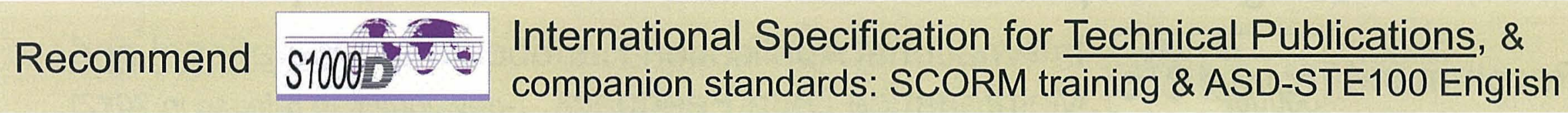

- Supply Support - Focus Points:

- Spares/provisioning, bill of materials (BOM), supply chain, etc.

Recommend International Specification for Materiel Management 


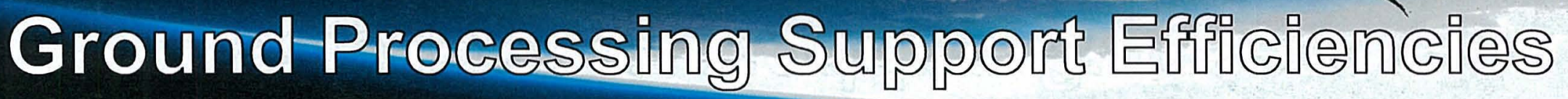

- Maintenance Planning \& Management - Focus Points:

- Maintenance concept \& execution, Level of Repair Analysis (LORA), Failure Modes Effects and Criticality Analysis (FMECA) required repair times determination, Reliability-Centered Maintenance (RCM), etc.

- Common tool: Logistic Support Analysis/Record (LSA/LSAR)

- Some LSAs for space now; NASA is considering S3000L \& other LSAs Recommend $\begin{array}{ll}\text { S3000E } & \text { International Procedure Specification for Logistic Support } \\ \text { Analysis (LSA) }\end{array}$

Recommend International Procedural Handbook for Developing

Scheduled Maintenance Programs (-scheduled to release in 2011)

\section{- Integrate IPS Elements for Optimization \& Interoperability}

- S5000F being developed to feedback data from others for optimization

Recommend S5000 ? ? International Application Handbook for Operational and Maintenance Data Feedback (-developing to release in 2012)

- S-series standards are designed to use ISO 10303-239 PLCS as a hub Recommend ISO 10303-239 Product Life Cycle Support (PLCS), part of the STEP Standard 


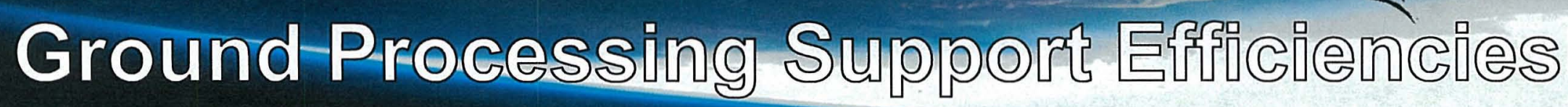

- Optimal Efficiencies with IT Integration to Enable Interoperability

- Recommend S-series Suite of Standards, with PLCS Standard

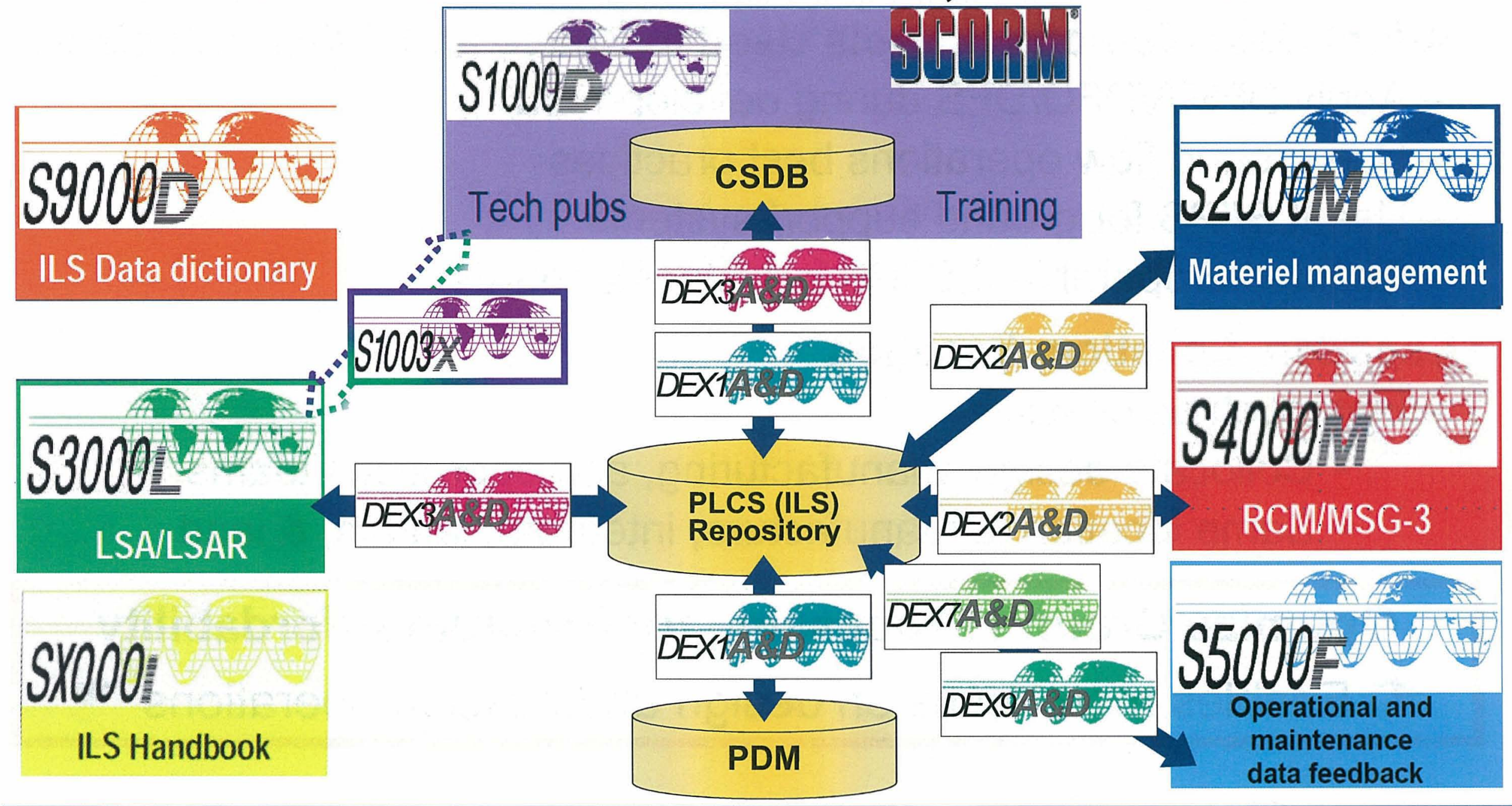




\section{Conclusion}

- Ground Processing Is a Key to Affordability

- $85 \%$ of life cycle costs

- Adopt Best Methods \& Tools Used in Space and Other Industries

- Apply DFMA/DFO/DFS during development

- Use ground flow operations best practices

- Use ILS/IPS for ground support systems

- Enact interoperable ILS/IPS industry standards

- Location, Location, Location

- Inasmuch as possible,

- Collocate design, manufacturing, and operations teams

- Same location to manufacture, integrate, launch, \& land

\section{Optimize Ground Processing for Program Affordability}

- Enables more focus on design and mission operations 


\title{
Questions?
}

\section{"The heart of the prudent acquires knowledge, And the ear of the wise seeks knowledge."}

\author{
Proverb
}

\section{QUESTIONS?}

